NBER WORKING PAPER SERIES

\title{
INCOME GROWTH AND THE DISTRIBUTIONAL EFFECTS OF URBAN SPATIAL SORTING
}

\author{
Victor Couture \\ Cecile Gaubert \\ Jessie Handbury \\ Erik Hurst
}

Working Paper 26142

http://www.nber.org/papers/w26142

\author{
NATIONAL BUREAU OF ECONOMIC RESEARCH \\ 1050 Massachusetts Avenue \\ Cambridge, MA 02138 \\ August 2019, Revised January 2020
}

We thank Hero Ashman and Allison Green for outstanding research assistance. We thank Treb Allen, David Atkin, Don Davis, Jonathan Dingel, Ingrid Ellen, Alessandra Fogli, Ed Glaeser, Gabriel Kreindler, Christopher Palmer, Steve Redding, Andres Rodriguez-Clare, Jung Sakong, Yichen Su, Jacob Vigdor, and Jonathan Vogel for many helpful comments as well as seminar participants at Berkeley, Baruch, Chicago, Edinburgh, Georgetown, HEC Montreal, Illinois, LSE, Northwestern, Notre Dame, NYU, Oxford, Penn State, the Princeton IES Workshop, Stanford, UCLA, Toronto, Warwick, Wharton, Yale, the 2017 Federal Reserve Bank of Richmond conference on "Understanding Urban Decline," the 2018 European and U.S. Urban Economic Association meetings, the 2019 Barcelona GSE Summer Forum and various NBER programs. Victor Couture thanks the Fisher Center for Real Estate and Urban Economics at UC Berkeley for financial support. Cecile Gaubert thanks the Fisher Center for Real Estate and Urban Economics and the Clausen Center for International Business and Policy at UC Berkeley for financial support. Jessie Handbury thanks the Zell/Lurie Real Estate Center at Wharton for financial support. The views expressed herein are those of the authors and do not necessarily reflect the views of the National Bureau of Economic Research.

NBER working papers are circulated for discussion and comment purposes. They have not been peer-reviewed or been subject to the review by the NBER Board of Directors that accompanies official NBER publications.

(C) 2019 by Victor Couture, Cecile Gaubert, Jessie Handbury, and Erik Hurst. All rights reserved. Short sections of text, not to exceed two paragraphs, may be quoted without explicit permission provided that full credit, including () notice, is given to the source. 
Income Growth and the Distributional Effects of Urban Spatial Sorting

Victor Couture, Cecile Gaubert, Jessie Handbury, and Erik Hurst

NBER Working Paper No. 26142

August 2019, Revised January 2020

JEL No. D11,R12,R13,R23

\begin{abstract}
We explore the impact of rising incomes at the top of the distribution on spatial sorting patterns within large U.S. cities. We develop and quantify a spatial model of a city with heterogeneous agents and non-homothetic preferences for neighborhoods with endogenous amenity quality. As the rich get richer, demand increases for the high quality amenities available in downtown neighborhoods. Rising demand drives up house prices and spurs the development of higher quality neighborhoods downtown. This gentrification of downtowns makes poor incumbents worse off, as they are either displaced to the suburbs or pay higher rents for amenities that they do not value as much. We quantify the corresponding impact on well-being inequality. Through the lens of the quantified model, the change in the income distribution between 1990 and 2014 led to neighborhood change and spatial resorting within urban areas that increased the welfare of richer households relative to that of poorer households, above and beyond rising nominal income inequality.

Victor Couture

University of California, Berkeley

Haas School of Business

2220 Piedmont Avenue

Berkeley, CA 94720-1900

couture@berkeley.edu

Cecile Gaubert

Department of Economics

University of California, Berkeley

687 Evans Hall

Berkeley, CA 94720

and NBER

cecile.gaubert@berkeley.edu

Jessie Handbury

The Wharton School

University of Pennsylvania

1463 Steinberg-Dietrich Hall

Philadelphia, PA 19104

and NBER

handbury@wharton.upenn.edu

Erik Hurst

Booth School of Business

University of Chicago

Harper Center

Chicago, IL 60637

and NBER

erik.hurst@chicagobooth.edu
\end{abstract}

A data appendix is available at http://www.nber.org/data-appendix/w26142 


\section{Introduction}

Over the last three decades income inequality in the United States has grown sharply, with income growth concentrated at the top of the earnings distribution. At the same time, higher income individuals have been moving back into urban cores, transforming downtown neighborhoods and sparking a policy debate on gentrification within many US cities. We posit that these trends are linked. Rich households are more likely to live downtown than middle-income households in part because these areas afford them access to local amenities like restaurants or entertainment venues. ${ }^{1}$ As the incomes of the rich increase, aggregate demand for neighborhoods with these luxury urban amenities rises and more of them choose to reside downtown, triggering the redevelopment of previously low income neighborhoods.

In this paper, we develop a model to formalize this mechanism. We use the model to quantify how top income growth contributes to neighborhood change, measure the associated welfare effects, and guide policy designed to curtail the resulting gentrification. The key model features include (i) non-homothetic preferences for location: rich and poor households make systematically different location choices within a given city and (ii) endogenous neighborhood development: the quality of amenities in city neighborhoods responds endogeneously to demand. The macro and trade literature have highlighted that a rise in nominal income inequality can induce an even stronger increase in real income inequality in the presence of such non-homothetic preferences and endogeneous supply responses. We apply this logic to the endogenous development of neighborhoods within cities.

Figure 1 motivates our analysis by summarizing the changes in spatial sorting by income in large U.S. cities from 1970 to today. Specifically, the figure plots the propensity of households in each Census income bracket to live "downtown" in 1970, 1990, and 2014 relative to the average household in each period. Downtown is defined as the set of constant boundary Census tracts closest to the city center that account for $10 \%$ of each CBSA's population in 2000 . We restrict our analysis to the 100 largest CBSAs based on 1990 population. ${ }^{2}$ The figure documents that the propensity to live downtown is U-shaped in household income, and has been so since at least 1970. As is well known, poorer households are over-represented in downtown areas of a CBSA. A perhaps lesser known fact is that richer households are also systematically over-represented downtown: above $\$ 100,000$, the propensity to live downtown increases with income. Notably, Figure 1 also shows that the U-shape has shifted in the recent period. Between 1990 and 2014, the rich have become more likely to reside downtown, and the poor less so.

We develop a model of a stylized city that accommodates such U-shape sorting patterns and then use the model to investigate how much of the recent change in the U-shape can be traced back to changes in the income distribution over time. In the model, households are heterogeneous in incomes and choose where to live among neighborhoods that offer different qualities of amenities and

\footnotetext{
${ }^{1}$ For example, Aguiar and Bils (2015) estimate that restaurant meals and non-durable entertainment are among the goods with the highest income elasticities. Couture and Handbury (2017) document that downtown areas of major cities have a higher density of such amenities.

${ }^{2}$ See Appendix A for a more detailed discussion of the construction of this figure. In this appendix we also show that the patterns in Figure 1 hold within detailed demographic groups.
} 
Figure 1: Downtown Residential Income Propensity by Income

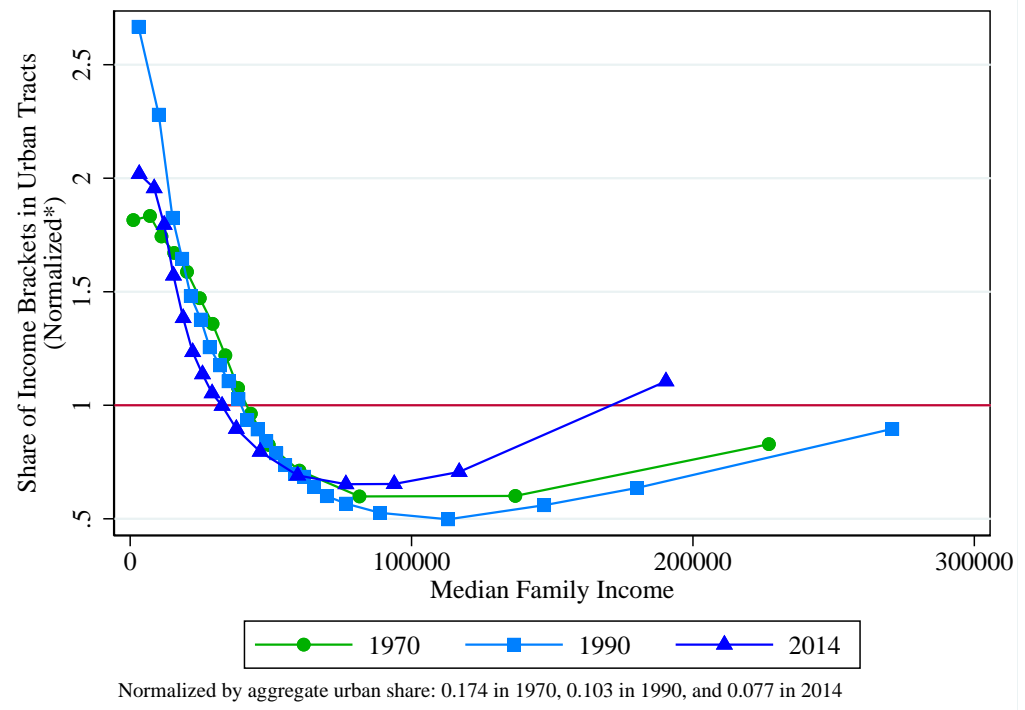

Note: This figure shows sorting by income in 100 large CBSAs in 1970, 1990, and 2014. The 100 CBSAs are those with the largest population in 1990. Each point plots the share of families in a given Census income bracket who reside downtown in a given year - normalized by the share of all families who reside downtown that year - against the median family income (in 1999 dollars) of that Census income bracket in that year. The downtown area of each CBSA is defined as the set of tracts closest to the center of each CBSA that account for $10 \%$ of that CBSA's population in 2000. The number of points on the graph is limited by the number of income brackets reported by the Census for tract-level data. We compute the median income in each bracket using IPUMS microdata for the corresponding year in the 100 largest CBSAs. The IPUMS microdata is adjusted for top-coding using the generalized Pareto method, as described in Appendix C.

housing. Households trade off neighborhood attractiveness against cost of living. This cost depends on local housing prices and on the cost of commuting to work. Preferences for neighborhoods are non-homothetic: households with higher incomes are more willing to pay the higher cost of living in desirable neighborhoods. On the supply side, neighborhoods are built by private developers who compete for land within each area of the city. As top incomes grow, demand for high quality neighborhoods downtown rises leading to an increase in prices throughout downtown, including in low quality neighborhoods where the poor live. An increase in the supply of high quality neighborhoods, and an associated decrease in the variety of low quality neighborhoods, amplifies this price mechanism. Through these mechanisms, an influx of richer households downtown unambiguously hurts the lower income renters residing there.

The model also builds in mitigating forces through which an influx of higher incomes downtown could benefit incumbent poor households. First, households travel to consume amenities outside of their neighborhood of residence. An improvement in the quality of other neighborhoods in the city benefits all households who travel to consume these amenities, beyond its residents. Second, local governments build public amenities like parks or schools that benefit all households in a given location. The provision of public amenities increases as the tax base downtown increases. Third, some low income downtown residents own their homes, and hence reap the benefits of house price 
appreciation. Given these mitigating forces, how an influx of richer households into downtown areas affects the well-being of lower income households on net is a quantitative question.

Before fully estimating the model, we use micro data to provide evidence for the model's key sorting mechanism. We exploit changes in spatial sorting patterns in response to a CBSA-wide income shock, driven by plausibly exogenous variation in labor demand across cities. Our instrumental variable estimation shows that an income shock raises house prices and amenity quality downtown more than in the suburbs and induces the rich to re-sort into downtowns. These results suggest that income growth triggers within-city spatial sorting disproportionately drawing the rich downtown, consistent with our model of non-homothetic location choices.

This micro evidence yields an estimate for the elasticity that governs how income-dependent within-city location choices are, a key parameter in our quantitative analysis. A second important model elasticity governs the magnitude of the gains from accessing a variety of non-tradable amenities in the city. We identify this parameter using a gravity equation for amenity consumption, derived from the model, and a rich novel database of smartphone location data that traces the extent to which individuals from different neighborhoods travel to different venues. After fully quantifying the model, we show that it is able to replicate the fact that downtown areas are disproportionately populated by both very low and very high earners, mimicking the U-shape in Figure 1. In the model, low income households minimize the costs of housing and commuting by residing in low quality neighborhoods downtown. At the same time, higher income households are attracted downtown by the density of high quality, high amenity luxury neighborhoods offered there.

We use the quantified model to back out how much of the change in spatial sorting between 1990 and 2014 comes from changes in the income distribution. We find that (i) the increased incomes of the rich since 1990 are causing a phenomenon that looks like urban gentrification the in-migration of higher income residents downtown causes the amenity mix of neighborhoods to change - and (ii) this mechanism can explain roughly one-half of the urbanization of the rich (top income decile) and roughly one-half of the suburbanization of the poor (bottom income decile). ${ }^{3}$ These findings highlight that, while other forces outside of the model are also arguably contributing to neighborhood change over the last few decades, the rising incomes of the rich play a quantitatively important role in the recent rise in gentrification of urban centers.

To further validate the model, we present additional counterfactual analyses. First, we show that a similar procedure applied to the 1970-1990 change in the income distribution leads to a much more limited spatial sorting response compared to 1990-2014, like in the data. While incomes increased during the 1970-1990 period, our analysis suggests that there was not a sufficiently large increase in

\footnotetext{
${ }^{3}$ Throughout the paper, we often use "neighborhood change" of low income neighborhoods and "gentrification" interchangeably. We realize that gentrification is a complex process with many potential definitions and drivers. Our interpretation is closest to the definition in the Merriam-Webster dictionary that defines gentrification as "the process of renewal and rebuilding accompanying the influx of middle-class or affluent people into deteriorating areas that often displaces poorer residents." Our paper is not intended to explore all potential underlying causes of neighborhood gentrification. Rather, we wish to focus on the dimension of gentrification that follows the rise in top incomes. Specifically, we focus on the interaction of rising top incomes, non-homothetic preferences for urban amenities, and endogenous spatial responses.
} 
households at very high income levels to trigger much neighborhood change downtown. Second, we show that the model also performs quite well at explaining cross-CBSA variation in spatial sorting during the 1990 to 2014 period. We feed into our model changes in the income distribution that are CBSA specific. The resulting model predictions match well the actual patterns of neighborhood change observed empirically within each CBSA. These additional counterfactuals further highlight the ability of our model to match empirical patterns linking changes in the income distribution and changes in the propensity of high income individuals to locate downtown.

We next use the quantified model to study the normative implications of changes in spatial sorting. We find that the 1990-2014 increase in income inequality triggered an even larger increase in well-being inequality once accounting for changes in neighborhood quality and spatial sorting. Quantitatively, mitigating forces like the public provision of amenities are not strong enough to overcome the base mechanism, which hurts the poor primarily through higher rents. Overall, we find that accounting for endogenous spatial sorting responses increased well-being inequality between the top and bottom deciles of the income distribution by 1.7 percentage points (on a base of 19 percentage points) during the past three decades. We further estimate that the welfare of low income renters was actually reduced by $0.5 \%$ from the resulting gentrification stemming from top income growth during this period.

Finally, we use the model to study the effect of stylized 'anti-gentrification' policies, for instance one that taxes housing in high quality neighborhoods downtown to subsidize housing in low quality neighborhoods downtown. We find that such policies can be effective in maintaining a diverse income mix downtown. However, these policies do not overturn the increase in well-being inequality that we find for 1990-2014, as price and quality upgrades are to a large extent pushed to the suburbs. In contrast, a policy that relieves housing supply constraints downtown mitigates the negative welfare impact of neighborhood change on the poor, but does not curb the influx of the rich into downtowns.

Related Literature This paper contributes to four main literatures. First, a growing literature studies how nominal income inequality growth can induce even stronger real income inequality growth in models with non-homothetic preferences and endogeneous supply responses, especially in the context of international trade. ${ }^{4}$ We apply this logic to the endogenous development of neighborhoods within cities.

Second, we contribute to the quantitative spatial economics literature reviewed in Redding and Rossi-Hansberg (2017), more specifically to the strand that studies the internal structure of cities (Ahlfeldt et al. (2015); Allen et al. (2015); Redding and Sturm (2016)). Different from our approach, these papers feature homogeneous workers, homothetic preferences, and model a specific city with no extensive margin of within-city locations. We propose a stylized model of a representative city

\footnotetext{
${ }^{4}$ Faber and Fally (2017) show that more productive firms target wealthier households; Jaravel (2018) shows that innovation is skewed towards the growing top income market segment; Fajgelbaum et al. (2011), Fajgelbaum and Khandelwal (2016) and Faber (2014) study the welfare consequences of trade across the income distribution. Dingel (2016) provides evidence that the higher income residents generate endogenous supply of higher quality products in U.S. cities.
} 
that allows us to model the extensive margin: the number and quality of neighborhoods in a city is endogenous. Our approach also uniquely studies spatial sorting and well-being across the full distribution of incomes, with a common non-homothetic preference structure across incomes. ${ }^{5}$ The model's core mechanisms are drawn from Fajgelbaum et al. (2011) and relate to the assignment model of Davis and Dingel (2019). Our framework retains the tractability of quantitative spatial models, which allows us to take it to the data and quantify the impact of policies on neighborhood change and welfare. ${ }^{6}$ Our paper therefore also complements recent work examining the welfare implications of urban policies by Diamond et al. (Forthcoming), Eriksen and Rosenthal (2010), Baum-Snow and Marion (2009), Diamond and McQuade (2019) and Hsieh and Moretti (2019).

Third, we contribute to the literature that studies changes in spatial sorting over time. In an early contribution, Gyourko et al. (2013) show that the increase in high incomes nationally can explain the upward co-movement of incomes and house prices observed in "superstar cities." Diamond (2016) shows that homophily among the college educated amplifies sorting behavior across cities. Different from Diamond (2016), households have identical non-homothetic preferences in our model. Changes in consumption and location choices stem from changes in income. Furthermore, we model the economics behind the endogenous supply of neighborhoods within a city that fuels increases in welfare inequality. Contemporaneous work also studies welfare inequality within cities. For example, Fogli and Guerrieri (2019) focus on educational outcomes while Su (2018b) emphasizes the role of rising value of time for high skilled workers. Our focus on urban amenities as an important dimension of neighborhood heterogeneity follows the early insights of Brueckner et al. (1999) and Glaeser et al. (2001) on the "consumer city." Recent work by Almagro and Dominguez-Iino (2019) and Hoelzlein (2019) also study how endogenous amenities reinforce sorting by income within cities.

Fourth, our approach complements a flourishing literature that highlights various causes and consequences of gentrification and neighborhood change. ${ }^{7}$ Within this literature, our paper builds on a growing strand that concludes that amenities play an important role in explaining demographic shifts downtown, relative to changing job locations (Glaeser et al. (2001), Baum-Snow and Hartley (2018), Couture and Handbury (2017), Su (2018b)). Couture and Handbury (2017), for example, document rising average commute distance for high-wage workers from 2002 to 2011 despite their moving into downtown areas, and rising propensity to reverse-commute among the rich, i.e., to live downtown but work in the suburbs. These findings illustrate that changing job location or changing taste for commutes alone are unlikely to rationalize the rising propensity of high-skilled workers to

\footnotetext{
${ }^{5}$ Our paper complements recent work by Tsivanidis (2019) who uses Stone-Geary preferences to study the distributional effects of infrastructure investment in Bogota across two skill groups. In country-wide spatial equilibrium models, Peters et al. (2018) use PIGL preferences of a representative agent to study structural change across U.S. counties and Fajgelbaum and Gaubert (2018) study optimal spatial policies in models with heterogeneous workers who have heterogeneous but homothetic preferences over endogenous city amenities.

${ }^{6}$ Gaigne et al. (2017) theoretically analyze an extension of a classic linear city model with jobs and amenities exogenously given at different locations on the line, in which non-homothetic preferences generates heterogeneous spatial sorting.

${ }^{7}$ See, for example, Guerrieri et al. (2013), Edlund et al. (2019), Ellen et al. (2019), Berkes and Gaetani (2018), Vigdor et al. (2002), Lance Freeman (2005), McKinnish et al. (2010); Ellen and ORegan (2010), Ding et al. (2016); Brummet and Reed (2019), Meltzer and Ghorbani (2017), Lester and Hartley (2014), and Autor et al. (2017).
} 
live downtown. We contribute to this literature by documenting and quantifying a novel channel (rising top incomes, coupled with income effects on location choice), as well as methodologically, by providing a quantitative model that allows for policy assessment.

The rest of the paper proceeds as follows. Section 2 lays out the model and its properties. Section 3 presents the data and provides empirical evidence for the main mechanism of the model, while the model is fully quantified in Section 4. The impact of the 1990-2014 change in income distribution on within-city spatial sorting is presented in Section 5. Section 6 discusses the corresponding normative and policy implications.

\section{A model of the residential choice of heterogeneous households}

We begin by developing a benchmark model of a representative city where households have heterogeneous incomes. Households with different incomes make different residential choices in the city; in turn, the urban landscape responds to the economic composition of the city. The benchmark model is stylized so as to emphasize its key mechanisms. We will later incorporate more realistic features to guide the empirical analysis. Additional details are provided in Appendix B.

\subsection{Benchmark Model}

\subsubsection{Demand for neighborhoods}

Model setup The city is populated by households whose income $w$ is distributed according to a density $L(w)$. This income distribution is taken as a primitive of the model. One of our key objects of interest will be how the city equilibrium changes as the income distribution $L(w)$ changes.

Each household $\omega$ selects a neighborhood $r$ to reside in, trading-off quality of life in a given neighborhood against the corresponding cost-of-living. ${ }^{8}$ Specifically, they derive utility from the consumption of a freely traded good taken as the numeraire, as well as from the quality of life in their residential location, as summarized by the following indirect utility:

$$
v_{r}(\omega)=\left(\left(1-\tau_{r}\right) w^{\omega}-p_{r}\right) B_{r} b_{r}^{\omega}
$$

In this expression, $w^{\omega}$ is the wage of household $\omega, B_{r}$ is the quality of neighborhood $r$, and $b_{r}^{\omega}$ is household $\omega$ 's idiosyncratic preference for neighborhood $r$, which we detail below. In order to live in neighborhood $r$ and enjoy its residential amenities, households have to pay for one unit of housing, at rent $p_{r}$, and incur a commuting cost to work $\tau_{r}$. Households choose the neighborhood $r$ that maximizes their utility (1).

Neighborhoods $r$ are differentiated along several dimensions. First, they can be located in one of two broad areas indexed by $n$ : Downtown $(n=D)$ and the Suburbs $(n=S)$. Second, neighborhoods vary in their intrinsic quality, indexed by $j$, which captures the attractiveness of

\footnotetext{
${ }^{8}$ We make the implicit assumption that, in a first step that is not modeled, workers find jobs with income $w$ in the city. In a second step, they choose where to live within the city.
} 
local urban amenities as well as the quality of the housing stock. Third, within a location-quality pair $(n, j)$, neighborhoods are differentiated horizontally - but symmetric, as we detail below. Households have an idiosyncratic preference for each neighborhood $b_{r}^{\omega}$ drawn from a Generalized Extreme Value distribution:

$$
F\left(\left\{b_{r}\right\}\right)=\exp \left(-\left[\sum_{n, j}\left(\sum_{r \in \mathcal{R}_{n j}} b_{r}^{-\gamma}\right)^{-\frac{\rho}{\gamma}}\right]\right) .
$$

where $\mathcal{R}_{n j}$ denotes the set of neighborhoods of quality $j$ in area $n$ of the city. This nested structure captures the intuitive feature that the preferences of a given household are more correlated between neighborhoods of the same quality and located in the same part of the city, making them closer substitutes, than they are for neighborhoods of different quality or location. Specifically, the parameter $\rho$ captures the substitutablility of neighborhoods of different $(n, j)$ types, while $\gamma$ governs the substitutablility of horizontally differentiated neighborhoods of the same $(n, j)$ type, with $\rho<\gamma$.

We assume for simplicity that horizontally differentiated neighborhoods are otherwise symmetric within each $(n, j)$ pair, so that $B_{r}=B_{n j}$. We further assume that within each broad area $n$, neighborhoods are symmetric in their access to jobs. Downtown neighborhoods are characterized by a better access to jobs than those in the Suburbs $\left(\tau_{D}<\tau_{S}\right)$, because of shorter distances and a higher availability of public transportation Downtown. Finally, note that housing prices will be identical in equilibrium across neighborhoods within each location-quality pair, so that $p_{r}=p_{n j}$.

Our demand function in (1) resembles a conventional discrete choice of location setup, widely used in the quantitative spatial economics literature, except that it features location choices that are income dependent. We discuss these sorting properties next, before closing the benchmark model with a discussion of neighborhood development.

Residential Sorting by Income Given expression (1) and making use of the model's symmetry, the share of households who locate in a neighborhood of type $(n, j)$ among households with income $w$ is:

$$
\lambda_{n j}(w)=\frac{V_{n j}^{\rho}(w)}{\sum_{n^{\prime}, j^{\prime}} V_{n^{\prime}, j^{\prime}}^{\rho}(w)},
$$

where $V_{n j}(w)$ is the inclusive value of all neighborhoods of type $(n, j)$ for a household with income $w$ that can simply be summarized as:

$$
V_{n j}(w)=\tilde{B}_{n j}\left(w-\tilde{p}_{n j}\right)
$$

where

$$
\tilde{B}_{n j} \equiv B_{n j} N_{n j}^{\frac{1}{\gamma}}\left(1-\tau_{n}\right)
$$


is a model-consistent measure of the attractiveness of option $(n, j)$, while

$$
\tilde{p}_{n j}=\frac{p_{n j}}{1-\tau_{n}}
$$

is the corresponding cost-of-living index. We discuss the micro-foundation of these quality and cost-of-living terms later in this section. For now, note that $N_{n j}$ is the endogenous number of neighborhoods of a given area-quality type, and that utility increases with $N_{n j}$ through a love of variety effect: given the idiosyncratic preferences (2), more neighborhoods to choose from leads to a higher average utility.

Examining (3) and (4), we see that, at all levels of incomes, the propensity of a household to reside in a given neighborhood depends positively on the quality of its amenities and negatively on its cost of living. More interesting, across incomes, the utility of higher income households is less sensitive to higher costs of living. This yields residential sorting of households by income, as summarized below:

Proposition 1. High income households are over-represented in high cost-of-living neighborhoods.

Proposition 1 stems from the fact that $\frac{\partial^{2} \log V_{n j}(w)}{\partial w \partial \tilde{p}_{n j}}>0$, or equivalently $\frac{\partial^{2} \log \lambda_{n j}(w)}{\partial w \partial \tilde{p}_{n j}}>0$. This result comes from assuming that each household consumes one unit of housing, which makes higher income households less sensitive to house prices so, all else equal, they are over-represented in expensive neighborhoods. We would obtain a similar result if utility was Stone-Geary between the consumption of tradable good and housing, with a minimum housing requirement. ${ }^{9}$

Applying the result from Proposition (1) with a focus on commuting costs, we also find that $\frac{\partial^{2} \log \lambda_{n j}(w)}{\partial w \partial \tau_{n}}>0$, i.e., high income households are over-represented in higher commuting cost neighborhoods. This property of the model echoes a traditional explanation put forward in the urban literature for why poorer households often make the choice to live downtown: better access to jobs downtown, in particular given the availability of public transportation there.

The intensity of sorting by income in the city is crucially shaped by the preference parameter $\rho$. Indeed, the relative propensity to live in various neighborhood types by income can be written as:

$$
\frac{\lambda_{n j}(w) / \lambda_{n j}\left(w^{\prime}\right)}{\lambda_{n^{\prime} j^{\prime}}(w) / \lambda_{n^{\prime} j^{\prime}}\left(w^{\prime}\right)}=\left[\frac{\left(w-\tilde{p}_{n j}\right) /\left(w^{\prime}-\tilde{p}_{n j}\right)}{\left(w-\tilde{p}_{n^{\prime} j^{\prime}}\right) /\left(w^{\prime}-\tilde{p}_{n^{\prime} j^{\prime}}\right)}\right]^{\rho},
$$

so that:

Lemma 1. The intensity of income-based residential sorting increases with $\rho$, all else equal.

\footnotetext{
${ }^{9}$ In contrast to what we do here, the literature in economic geography frequently models housing consumption assuming Cobb-Douglas preferences, which deliver a constant expenditure share of housing and a unit income elasticity of housing. This assumption is well suited for models of location choice across cities with homogeneous workers, as shown by Davis and Ortalo-Magne (2011). They compute, city by city, the distribution across households of expenditure on housing divided by income, and show that the median of this distribution is stable across cities. In contrast, our model focuses on within-city sorting and on heterogeneous incomes. Across incomes, Aguiar and Bils (2015) show using CEX data that housing consumption has an income elasticity that is lower than 1 . Our model assumption is better suited than one relying on Cobb-Douglas preferences to capture the empirical fact that the expenditure share on housing decreases with income, as we show in Figure 6 below.
} 
The higher is $\rho$, the more richer households are over-represented in expensive neighborhoods, all else equal $\left(\frac{\partial}{\partial \rho}\left(\frac{\partial^{2} \log \lambda_{n j}(w)}{\partial w \partial p_{n j}}\right)>0\right)$. In that sense, the parameter $\rho$ governs the strength of nonhomotheticity in location choice. This makes $\rho$ a particularly important parameter to estimate in our quantitative exercise.

We now turn to a key stylized fact that our model aims to capture: the U-shaped propensity to live Downtown by income, established empirically in Figure 1. In this case, our object of interest is the share of households that lives Downtown at each level of income, $\lambda_{D}(w)=\sum_{j} \lambda_{D j}(w)$. We focus on the specification that we retain in quantification, with two quality tiers $j=\{L, H\}$, where $L$ and $H$ indicate low and high quality neighborhoods. In that case, there are four $(n, j)$ neighborhood types in the city: $D H, D L, S H$, and $S L$. We get the following result:

Lemma 2. The share of households living Downtown is a U-shaped function of income if the following condition holds:

$$
\frac{p_{D L}}{1-\tau_{D}}<\frac{p_{S L}}{1-\tau_{S}}<\frac{p_{S H}}{1-\tau_{S}}<\frac{p_{D H}}{1-\tau_{D}} .
$$

Proof. To establish this result, it is useful to define $\nu_{n j}(w) \equiv\left(w-\tilde{p}_{n j}\right)^{-1}$, a measure of cost of living relative to income: $\nu_{n j}(w)$ increases with cost of living in $(n, j)$ and decreases with income $w$. The share of households living in each type of neighborhood varies with income as follows:

$$
\frac{\partial \log \lambda_{n j}(w)}{\partial w}=\rho\left[\nu_{n j}(w)-\bar{\nu}(w)\right]
$$

where $\bar{\nu}(w)=\sum_{n, j} \lambda_{n j}(w) \nu_{n j}(w)$. Equation (9) implies that the share of households living in a neighborhood $(n, j)$ rises with income at income $w$ if and only if neighborhoods $(n, j)$ are costlier than the average neighborhood where households with income $w$ live. In particular, it implies that the share of households living in the most expensive neighborhood in the city necessarily increases with income, and the share of households living in the least costly neighborhood of the city necessarily decreases with income. For $\lambda_{D}(w)$, we have:

$$
\frac{\partial \log \lambda_{D}(w)}{\partial w}=\lambda_{L \mid D}(w) \frac{\partial \log \lambda_{D L}(w)}{\partial w}+\lambda_{H \mid D}(w) \frac{\partial \log \lambda_{D H}(w)}{\partial w},
$$

where $\lambda_{j \mid D}(w)$ is the probability that a household at income $w$ lives in quality $j$ conditional on residing downtown. By the argument made above, $\frac{\partial \log \lambda_{D L}(w)}{\partial w} \leq 0$, while $\frac{\partial \log \lambda_{D H}(w)}{\partial w} \geq 0$, given the ordering of cost-of-living in (8). Similar derivations show that, in addition, $\frac{\partial \lambda_{L \mid D}(w)}{\partial w} \leq 0$ while $\frac{\partial \lambda_{H \mid D}(w)}{\partial w} \geq 0$. Taken together, these comparative statics deliver the result that $\frac{\partial \lambda_{D}(w)}{\partial w} \leq 0$ for low $w$, while $\frac{\partial \lambda_{D}(w)}{\partial w} \geq 0$ for high $w$ : the share of households living Downtown is a U-shaped function of income, i.e. both the very rich and the very poor are over-represented downtown.

When cost-of-living is ordered as in (8), high income households are attracted downtown by high quality amenities provided in expensive neighborhoods, while low income households are attracted downtown by a relatively low cost of living (taking into account commuting) in low quality neighborhoods. Up to this point, we have characterized the properties of the model on the demand 
side, given price and quality of various neighborhood options. We now close the model with an endogenous supply of neighborhoods of various qualities and prices in the city.

\subsubsection{Closing the Model: Neighborhood Development}

Setup Neighborhoods are supplied by private developers, who choose the quality and location $(n, j)$ of the neighborhood they develop. Developers build housing units $H_{n j}$ of quality $j$ in location $n$ using equipped land $K_{n}$ through a linear production function:

$$
H_{n j}=\frac{K_{n}}{k_{n j}}
$$

where $k_{n j}$ denotes the land requirement for one unit of housing in neighborhoods $(n, j) .{ }^{10}$ The land requirement for housing increases with quality, i.e., $k_{n j}>k_{n j^{\prime}}$ when $j>j^{\prime}$, capturing the idea that housing units in higher quality neighborhoods are larger, and/or devote more space to residential amenities.

Land is provided by atomistic landowners. We assume that the city has two segmented land markets, one for each location $n \in\{D, S\}$. In each land market, there is perfect competition between landowners to rent out their land to developers, at unit rent $R_{n}$. We summarize the aggregate supply in land market $n$ with a reduced-form land-supply equation:

$$
K_{n}=K_{n}^{0}\left(R_{n}\right)^{\epsilon_{n}}, \text { for } n=\{D, S\}
$$

where $K_{n}$ is land supply in area $n$, and $K_{n}^{0}$ is a $n$-specific exogenous shifter for the size of downtown and the suburbs. The elasticity of land supply $\epsilon_{n}$ is higher in the suburbs $\left(\epsilon_{S}>\epsilon_{D}\right)$, capturing the notion that is is easier to expand equipped land at the outskirts of the city - through greenfield development and sprawl - than in densely built downtowns, where extending equipped land supply requires, for instance, building high-rises or redeveloping older warehouses or industrial areas.

Developers pay a fixed cost $f_{n j}$ to develop a differentiated neighborhood $r$ of type $(n, j)$. They then rent out housing units at price $p_{n j}$, which they set according to monopolistic competition. There is free entry of developers into each segment $(n, j)$ : the number $N_{n j}$ of neighborhoods of type $(n, j)$ adjusts so that the operating profit of a developer in neighborhood type $(n, j)$ just offsets the fixed cost, i.e.,

$$
f_{n j}=\frac{\int_{w} \lambda_{n j}(w)\left(p_{n j}-k_{n j} R_{n}\right) d L(w)}{N_{n j}}
$$

Equilibrium The pricing and entry behavior of developers are described in detail in Appendix B.3. Given unit housing demand and monopolistic competition, equations (3) and (4) lead to the

\footnotetext{
${ }^{10}$ In what follows, we use "equipped land" and "land" interchangeably. The model can easily be extended to feature an actual production function for equipped land that combines land area with capital, with a production function that can be $n, j$ specific. Given that this extension does not bring additional insight, we keep the formulation as simple as possible here.
} 
following housing pricing formula:

$$
p_{n j}=\frac{\gamma}{\gamma+1} k_{n j} R_{n}+\frac{1}{\gamma+1} \overline{\mathcal{W}}_{n j}
$$

where $\overline{\mathcal{W}}_{n j}$ is a measure of demand for a neighborhood of type $(n, j) .{ }^{11}$ Together with land rents, these prices pin down the operating profits of developers.

Definition 1. An equilibrium of the model is a distribution of location choices by income $\lambda_{n j}(w)$, housing prices $p_{n j}$, land rents $R_{n}$, and number of neighborhoods $N_{n j}$ such that (i) households maximize their utility; (ii) developers and landowners maximize profits; (iii) developers make zero profits; and (iv) the markets for land and housing clear.

Given the structure of the model, it is straightforward to show that an equilibrium of the model can be expressed in terms of changes relative to another reference equilibrium that has different primitives, such as a different city-level distribution of income. We leverage this approach in section $5 .{ }^{12}$ Having closed the model, we now discuss its general equilibrium properties, with a focus on tracing out how a given shock to the income distribution in the city impacts the relevant endogeneous variables of the model in equilibrium.

\subsection{Discussion: Effect of an Income Shock}

We have established above that sorting by income crucially depends on two endogenous neighborhood characteristics: an amenity composite and a cost-of-living composite $\left\{\tilde{B}_{n j}, \tilde{p}_{n j}\right\}$ defined in equations (5) and (6). Given that neighborhood developers respond to changes in demand, neighborhood characteristics change endogenously following an income shock to the city, as we discuss next.

To fix ideas, we study the effect of a small increase in the relative number of high-income households in the sense of first-order stochastic dominance (FOSD). Specifically, we consider a class of income distributions indexed by $\iota, L_{\iota}(w)$, ordered in the sense of FOSD, that is:

$$
\iota>\iota^{\prime} \Rightarrow L_{\iota}(w) \leq L_{\iota^{\prime}}(w)
$$

Starting at income distribution $L_{\iota}(w)$, we consider an infinitesimal increase in $\iota$. We focus on the specification we retain in the empirical analysis, with two layers of quality ( $H$ igh and Low) and an initial U-shape pattern of sorting by income under income distribution $L_{\iota}(w)$ as in Lemma 2.

The key sorting mechanism in the model in response to a shift in the income distribution acts through changes in housing prices, themselves driven by changes in land prices (equation (14)), as follows:

\footnotetext{
${ }^{11}$ Specifically, $\overline{\mathcal{W}}_{n j}=\frac{\int_{w}\left(1-\tau_{n}\right)\left(\left(1-\tau_{n}\right) w-p_{n j}\right)^{-1}}{\int_{w}\left(\left(1-\tau_{n}\right) w-p_{n j}\right)^{-1} \delta_{n j}(w) d L(w)}$ where $\delta_{n j}(w)=1\left\{\left(1-\tau_{n}\right) w-p_{n j}>0\right\}$.

${ }^{12}$ The model may give rise to multiple equilibria if the agglomeration effects at play are too strong compared to the dispersion forces, driven by the housing supply (in-)elasticity $\epsilon_{n}$ and the idiosyncratic preference for locations-quality types driven by $\rho$. Around our estimated parameter values, we have not found evidence for such multiple equilibria, suggesting that the calibrated $\epsilon_{n}$ and $\rho$ are low enough for equilibrium uniqueness.
} 
Lemma 3. Given a small increase $\iota$ in the relative number of high income households, land prices downtown increase: $\frac{\partial R_{D}}{\partial \iota} \geq 0$.

Proof. Combining equations (11) and (12) yields $R_{n}=\left(\frac{k_{n L} L_{n L}+k_{n H} L_{n H}}{K_{n}^{0}}\right)^{\frac{1}{\epsilon_{n}}}$, where we have defined $L_{n j}=\int_{w} \lambda_{n j}(w) d L(w)$. We have established above that $\frac{\partial \lambda_{D H}(w)}{\partial w} \geq 0$ while $\frac{\partial \lambda_{D L}(w)}{\partial w} \leq 0$, which yield $\frac{\partial L_{D H}}{\partial \iota} \geq 0$ while $\frac{\partial L_{D L}}{\partial \iota} \leq 0$ using classic results in monotone comparative statics. Given that $k_{D L}<k_{D H}$, we get that $\frac{\partial R_{D}}{\partial \iota} \geq 0$.

Through the market for land downtown, a demand shock for housing in high quality neighborhoods transmits to the entire downtown area - including in low quality neighborhoods. The intensity of the price increase is driven in particular by the housing supply elasticity $\epsilon_{D}$. A more inelastic supply downtown leads to steeper price increases there, all else equal. Given the impact of neighborhood prices on sorting, higher prices downtown tend to increase the share of high income residents and decrease the share of low income residents there, reinforcing the initial sorting patterns. This price mechanism is further reinforced by an amplification mechanism, as follows:

Lemma 4. Given a small increase $\iota$ in the relative number of high income households, the perceived quality of the most expensive neighborhood option increases $\left(\frac{\partial \tilde{B}_{D H}}{\partial \iota}>1\right)$, while the perceived quality of the least expensive neighborhood option decreases $\left(\frac{\partial \tilde{B}_{D L^{\prime}}}{\partial \iota}<1\right)$.

Proof. We use again the result that $\frac{\partial L_{D H}}{\partial \iota}>0$ while $\frac{\partial L_{D L}}{\partial \iota}<0$, combined with the free entry condition (13). This yields $\frac{\partial N_{D H}}{\partial \iota}>1$ while $\frac{\partial N_{D L}}{\partial \iota}<1$. Given the definition of $\tilde{B}_{j n}$ in 5 , Lemma 4 follows.

This result is quite intuitive: as the number of high income households increases in the city, there is increased demand for the luxury option $D H$ (the strength of which is governed by $\rho$ ), which results in an increased supply of such high quality neighborhoods downtown. Importantly, this endogenous increase in the supply of $D H$ neighborhood makes the $D H$ option even more attractive, because preferences for neighborhoods (equations (1) and (2)) embed a love of variety effect: the more options to choose from, the better the quality of the match between households and the neighborhood they choose. Through this love of variety effect, an increase in the supply of $D H$ neighborhoods increases the attractiveness of these types of neighborhoods, amplifying the price mechanism described above (governed by $\epsilon_{D}$ ) and further fueling the sorting of richer households downtown - a phenomenon that looks like urban gentrification. The intensity of this feedback loop depends on the elasticity of substitution across neighborhoods within an $n j$ pair, $\gamma$ as seen in equation (5). Our framework therefore formalizes a model for the gentrification of poorer neighborhoods in a city, as a result of demand and supply shifts for these neighborhoods.

\subsection{Extensions and Empirical Implementation}

Our benchmark model is stylized along several dimensions. Notably, the benchmark model's main mechanisms increase welfare inequality unambiguously in response to top income growth: endogenous supply responses (lemma 4) benefit the rich while hurting the poor through price effects 
(lemma 3). In this section, we develop model extensions that add nuance to this benchmark model, including mechanisms through which the inflow of richer households downtown may benefit the poor. For simplicity, we review these extensions one at a time, although we incorporate them jointly in a unified quantitative framework in sections 4 and 5.

\subsubsection{Consumption of amenities outside of one's neighborhood}

A limitation of the benchmark model is the assumption that increased variety of neighborhoods of a given $n j$ type only benefits inhabitants of that type of neighborhood. In reality, the gentrification of downtown neighborhoods can benefit all inhabitants of the city, to the extent they can travel to consume urban amenities there - as they do in the data. We embed this amenity consumption into the model, by assuming that non-housing expenditure is spent on a Cobb-Douglas aggregate of private urban amenities $a$ and the traded good $c$, and the demand for urban amenities for a household living in $r$ is a CES aggregate of amenity options in all neighborhoods. That is, the utility of household $\omega$ that lives in neighborhood $r \in \mathcal{R}_{n j}$ is:

$$
\begin{aligned}
& U_{r}(\omega)=B_{r}\left(\frac{a_{r}}{\alpha}\right)^{\alpha}\left(\frac{c_{r}}{1-\alpha}\right)^{1-\alpha} b_{r}^{\omega} \\
& a_{r}=\left(\sum_{r^{\prime}}\left(\beta_{j(r) j^{\prime}\left(r^{\prime}\right)}\right)^{\frac{1}{\sigma}}\left(a_{r r^{\prime}}\right)^{\frac{\sigma-1}{\sigma}}\right)^{\frac{\sigma}{\sigma-1}},
\end{aligned}
$$

where $a_{r r^{\prime}}$ is consumption of amenities in $r^{\prime}$ for a household living in $r, \sigma>1$ is the elasticity of substitution between amenities in different neighborhoods, and the disutility term $\beta_{j(r) j^{\prime}\left(r^{\prime}\right)}$ depends on the dissimilarity in quality between a household's own neighborhood and the destination neighborhood. ${ }^{13}$ Commuting to amenities is costly, with a cost that increases with distance. The cost of consuming amenities in neighborhood $r^{\prime}$ for a household living in $r$ is $d_{r r^{\prime}}^{\delta} p_{r^{\prime}}^{a}$, where $\delta$ governs how the cost of commuting to consume amenities in $r^{\prime}$ varies with the distance $d_{r r^{\prime}}$ between $r$ and $r^{\prime}$, and $p_{r^{\prime}}^{a}$ is the price of amenities in $r^{\prime}$. Given our symmetry assumptions, neighborhoods in $\mathcal{R}_{n j}$ offer the same price index for amenity consumption, $P_{n j}^{a}$.

These amenities are provided by the private developers, who build both housing units and retail space when they develop neighborhoods. Beyond renting out housing units, they operate non-tradable services like restaurants and entertainment options that are marketed to households living in the neighborhood as well as to those living in other parts of the city. Developers use $K^{h}$ and $K^{a}$ units of land to build $H_{n j}^{h}$ housing units and $H_{n j}^{a}$ retail areas of quality $j$ in location $n$. Land markets clear, accounting for demand coming from both housing units and retail space. Developers in the retail amenity sector are monopolistically competitive, so they set amenity prices,

\footnotetext{
${ }^{13}$ We normalize $\beta_{j j}=1$. Typically $\beta_{j j^{\prime}} \leq 1$ if $j \neq j^{\prime}$, so that households value horizontal differentiation within quality level, but to a lesser degree outside of their preferred quality type.
} 
denoted $p_{n j}^{a}$, at a constant markup over marginal costs, i.e.:

$$
p_{n j}^{a}=\frac{\sigma}{\sigma-1} k_{n j}^{a} R_{n}
$$

The equilibrium price for housing is still pinned down by (14) but is now denoted $p_{n j}^{h}$. The number $N_{n j}$ of neighborhoods of type $(n, j)$ adjusts so that $\pi_{n j}^{h}+\pi_{n j}^{a}-f_{n j}=0$, where $\pi_{n j}^{i}$ for $i=h, a$ is the operating profit of a developer of type $(n, j)$ in activity $i$.

Through this channel, households benefit from an increased supply of urban amenities outside of their own type of neighborhood. Quantitatively, the strength of this effect will be disciplined, first, by how much individuals consume amenities outside of their own type of neighborhood in the data. The sufficient statistic that captures this effect in the model is $S_{n j}^{m k}$, the share of expenditure on amenities spent on neighborhood of type $(m, k)$ for households living in neighborhood of type $(n, j)$, as detailed further in the Appendix:

$$
S_{n j}^{m k}=\frac{N_{m, k} d_{m m^{\prime}}^{-\delta}\left(R_{m}\right)^{1-\sigma}}{\sum_{n^{\prime}, j^{\prime}} N_{n^{\prime}, j^{\prime}} d_{n n^{\prime}}^{-\delta}\left(R_{n^{\prime}}\right)^{1-\sigma}} .
$$

Second, the strength of this channel is also driven by $\sigma$, which governs the love of variety in consumption of amenities across neighborhoods. Section 4 discusses how we discipline $S_{n j}^{m k}$ and $\sigma$ using novel smartphone data which tracks individual visits to urban amenities within a city.

\subsubsection{Publicly-financed amenities}

Another limitation of the benchmark model is that it does not account for the fact that higher income households moving downtown increase the tax base and hence the provision of public amenities in urban municipalities, whereby benefiting poor incumbent households. To capture this notion, we assume that part of the attractiveness of neighborhoods is driven by public amenities such as parks, public schools, or policing, financed by local governments. They respond to taxes according to:

$$
B_{n j}=B_{n j}^{o}\left(G_{n}\right)^{\Omega}
$$

where $G_{n}$ is local government spending in area $n, \Omega$ is the supply elasticity of public amenities, and $B_{n j}^{o}$ captures the part of amenities not determined by local government spending. Governments can levy taxes on local households, summarized by $T_{n}(w)$ for households with income $w$. Spending is equal to taxes levied in the location $n$ :

$$
G_{n}=\int L(w)\left(\sum_{j} \lambda_{n j}(w)\right) T_{n}(w) d w
$$

As the tax base downtown increases, government revenues $G_{n}$ increase, which raises amenities for all households downtown, irrespective of the quality of their neighborhood. 


\subsubsection{Home ownership}

The benchmark model is static, hence it cannot capture the important notion that, as neighborhoods downtown gentrify, homeowners in gentrifying neighborhoods reap the price appreciation of their home. We embed this notion in the quantitative model in a simple way, allowing for household income to depend not only on their labor income, but also on the capital appreciation of their real estate portfolio, denoted by $\chi(w)$. Combined with taxes described above, net household income becomes:

$$
\left(1-\tau_{n}\right) w+\chi(w)-T_{n}(w)
$$

We allow the real estate portfolio $\chi(w)$ to depend on household type $w$ to capture the corresponding heterogeneity in homeownership rates and initial locations in the data. As land prices in downtown neighborhoods increase, incumbent homeowners receive a capital gain on their housing stock making them better off compared to renters. The extent of this mitigating force is governed by $\chi(w)$ which we discipline empirically by matching homeownership rates by income in different locations.

\subsubsection{Change in Job Location}

Our focus is to isolate the effect of changes in income on changes in spatial sorting, through nonhomothetic preferences for neighborhoods. We have kept the model minimal on other dimensions that likely contribute, in part, to changes in sorting. Change in jobs location is one such dimension. The framework can be extended - at the cost of a more cumbersome exposition - to model the joint choice of workplace and residential location as in Ahlfeldt et al. (2015). This extension would allow us to account for the possibility that changes in job location triggers skill-dependent resorting, a different channel for changes in spatial sorting by income. However, we note that current evidence in the literature indicates that spatial job sorting plays little to no role in explaining recent downtown gentrification. First, Su (2018b) investigates job urbanization by skill from 1994 to 2010, and finds no difference in job location trends between high- and low-skilled jobs: they both suburbanize somewhat over that time period, at the same rate. Second, Baum-Snow and Hartley (2018) decompose the role of residential demand vs. labor demand in explaining 2000-2010 downtown gentrification. They conclude that labor demand plays little role. Third, Couture and Handbury (2017) conclude that high wage jobs - in the upper third of the wage distribution - do not urbanize fast enough from 2002-2011 to be an important driver of urban gentrification. ${ }^{14}$ Given the general conclusion in the urban literature that job location is not an important driver of recent urban gentrification, and given also the limited impact that commuting costs ultimately have on our quantification, we have refrained from complexifying the model in that dimension.

\footnotetext{
${ }^{14}$ Moreover, data from the U.S. Census shows that commuting times increased the most for downtown CBSA residents in the top income deciles between 1990 and 2014 (authors' calculations). This is consistent with the recent literature documenting the increased propensity of high income households living in urban centers to reverse commute - i.e., to live downtown and work in the suburbs.
} 
The mechanisms described in this subsection mitigate the adverse effect of an increase in income inequality on welfare inequality, while endogeneous neighborhood supply amplify the baseline price effect. The net effect of increased incomes of the rich on welfare inequality through spatial sorting is therefore ambiguous. We turn next to its quantification.

\section{Evidence on Spatial Sorting by Income}

In this section, we provide empirical evidence in support of the non-homothetic sorting mechanism at the heart of our model. The strength of that sorting mechanism pins down the parameter $\rho$, which will be important for the quantitative exercise that follows.

\subsection{Mapping Model to Data}

Our empirical work requires data on household location decisions and housing costs mapped into the spatial units employed in the model. Herein, we describe this mapping and summarize our main data sources. The full exposition of the data work is detailed in Appendix C.

Spatial Units and Classifications We equate the notion of a city to a Core-Based Statistical Area (CBSA), and that of a neighborhood to a census tract. All data are interpolated to constant 2010-boundary tracts and 2014-boundary CBSAs using the Longitudinal Tract Data Base (LTBD).

Within each CBSA, we define downtown as the set of tracts closest to the center of the CBSA that accounted for 10 percent of the CBSA's population in 2000. ${ }^{15}$ This spatial boundary of downtown is constant across all years. We refer to all remaining non-downtown tracts in each CBSA as suburban, so that tracts are either classified as downtown $(D)$ or suburban $(S)$. Appendix C.3 features maps showing which tracts in New York, Chicago, Philadelphia, San Francisco, Boston and Las Vegas are classified as downtown and suburban.

We pursue two different approaches to segment tracts into high and low quality. First, as our baseline approach, we define neighborhood quality using residential demographic composition. We draw from Diamond (2016), who shows that the college-educated share can proxy for endogenous amenities. Specifically, we classify a neighborhood to be high quality if at least 40 percent of residents between the ages of 25 and 65 have at least a bachelor's degree. Under this definition, 15, 22 , and 32 percent of census tracts in the top 100 CBSAs are respectively classified as high quality in 1990,2000 , and $2014 .^{16}$

Second, we classify neighborhoods using a proxy for the quality of local amenities. This proxy is an index of the quality of the restaurants located in a tract. We construct this index in two steps.

\footnotetext{
${ }^{15}$ We use the CBSA centers from Holian and Kahn (2012), who identify the coordinates returned by Google Earth for a search of each CBSA's principal city.

${ }^{16}$ We calibrate our model to moments based on initial 1990 quality definitions only, but rely on parameters estimated using time-series data. In theory, these parameter estimates could be affected by the fact that national education growth pushes the share of tracts with 40 percent or more college-educated upward between 1990 and 2014 . In practice, we control for this aggregate growth, relying only on cross-CBSA regressions that are invariant to national trends.
} 
We first leverage novel smartphone movement data (Couture et al., Work in Progress) to measure the quality of the 100 largest restaurant chains in the smartphone data. We define chain quality as the propensity of high-income individual to visit a given chain, relative to the propensity of the average individual, controlling for their relative proximity to establishments. ${ }^{17}$ Then, we classify a census tract as high or low quality using the National Establishment Time-Series (NETS) geocoded census of local restaurants in 2000 and 2012. A census tract is high quality for a given year if the average quality of its chain restaurants is higher than 1.1 - a cut-off chosen so that both definitions of quality yield a similar overall share of high quality tracts in year 2000.

In what follows, we present all our results for the college share quality measure. We demonstrate the robustness of our main estimation and counterfactual welfare results to the restaurant measure of neighborhood quality in the respective appendices for these sections.

Income and House Prices Our data on location choice by household income is from the 1990 Census and the 2012-2016 American Community Surveys (henceforth referred to as the "2014 ACS"). For each census tract, census tables report the number of households by income bracket. Since the boundaries of census brackets change over time, we define alternative income brackets that are constant in real terms over time. We summarize each constant bracket $m$ by the median income $w_{m}$ of households within the bracket. ${ }^{18}$ We drop brackets with median annual income smaller than $\$ 25,000$; given the presence of public housing, such households are not well represented by the model. ${ }^{19}$ In the CBSA-level analysis herein, $\lambda_{n j, c t}\left(w_{m}\right)$, denotes the share of households in income bracket $m$ that reside tract of area-quality $(n, j)$, out of all households in that CBSA $c$ at time $t$.

We measure house prices using Zillow's 2 Bedroom Home Value Index. Focusing on housing units of a given size helps control for the changing composition of housing units across different areas within a CBSA over time. Since house prices from Zillow are not available prior to 1996, we proxy for house prices in our initial period (1990) using data for years 1996-1998. ${ }^{20}$ We pool prices for years 2012-2016 for our end period (2014). Pooling over several years lessens the impact of transitory house prices fluctuations on our results. Finally, we convert Zillow's index for the median price of a 2 bedroom house in a given area and time period to an annual user cost. ${ }^{21}$ In the CBSA-level analysis herein, for example, $p_{n j, c t}^{h}$ denotes the annual user cost of a median priced 2 bedroom house in area-quality pair $(n, j)$ within CBSA $c$ at time $t$.

\footnotetext{
${ }^{17}$ The smartphone data contains 600 million visits to the 100 largest restaurant chains between 2016 and 2018 . We identify smartphone devices as high-income if their users reside in census blocks whose median resident income exceeds $\$ 100,000$. We measure propensity to visit a chain keeping only trips starting from home. Among the restaurant chains with the highest quality are smaller gourmet chains like Shake Shack (1st), Zoës Kitchen (2nd) and California Pizza Kitchen (3rd), as well as large national chains like Chipotle (6th), Panera Bread (7th), and Starbucks (14th).

${ }^{18}$ We reallocate households to these constant brackets assuming a uniform income distribution within each original bracket. For each interior bracket, $w_{m}$ is equal to its mid-point. We assign the top bracket the median income of that bracket in the 2000 IPUMS microdata.

${ }^{19}$ For instance, data from the department of Housing and Urban Development shows that in our downtowns in 2014 , about 30 percent of households earning between $\$ 5,000$ and $\$ 14,000$ in 1999 dollars lived in subsidized housing.

${ }^{20}$ House prices were relatively flat over the 1990 to 1995 period suggesting that this measurement issue is unlikely to bias our results in any meaningful way.

${ }^{21}$ The annual user cost of housing is 4.7 percent of house prices in 2000 , and 4.6 percent in 2014 according to data from the Lincoln Institute of Land Policy.
} 
All nominal variables including income and house prices are deflated to 1999 dollars using the urban CPI.

\subsection{Changes in the Income Distribution and Residential Sorting: Evidence}

We now provide empirical support for the sorting mechanism in the model. Our analysis uses data for 1990 and 2014 and focuses on the 100 CBSAs with the largest 1990 population.

\subsubsection{Descriptive Evidence}

This analysis aims to test whether changes in a city's income distribution generate different spatial sorting patterns for different income groups. As the city gets richer, our model predicts that richer households move downtown ("urbanize") relative to the average household, while poorer households move out ("suburbanize"). A first look at the data supports this prediction. We show that different income groups display systematically different spatial re-sorting patterns in cities that exhibit different city-wide income growth patterns. We use cross-city variation to estimate the correlation between city-wide income growth and spatial sorting for each income bracket $m$ with the following regression:

$$
\Delta \ln \left(\frac{\lambda_{D, c}\left(w_{m}\right) / \lambda_{D, c}}{\lambda_{S, c}\left(w_{m}\right) / \lambda_{S, c}}\right)=\alpha^{m}+\beta^{m} \Delta \text { Income }_{c}+\nu_{c}^{m},
$$

where $\Delta\left(\frac{\lambda_{D, c}\left(w_{m}\right) / \lambda_{D, c}}{\lambda_{S, c}\left(w_{m}\right) / \lambda_{S, c}}\right)$ is the change in the propensity of households at income level $w_{m}$ to reside downtown relative to all households in CBSA $c$ between 1990 and 2014. $\Delta$ Income $_{c}$ is one of two measures of income growth in $c$ during the same time period. The first measure is simply CBSA average income growth. The second measure is designed to capture top income growth, as the change in the ratio between the 95th percentile and the median of the CBSA income distribution. Note that $\beta^{m}>0$ implies that income group $m$ becomes more likely to reside downtown (relative to other income groups) in CBSAs that experienced more income growth across all areas.

Figure 2 plots point estimates and 95 percent confidence bands for the $\beta^{m}$ coefficients from regression (22). The left-hand plot shows that richer households urbanized more, and poorer households less, in CBSAs that experienced more average income growth. The right-hand plot shows even stronger patterns of urbanization of rich households and surburbanization of poor households in CBSAs with more top income growth. A 10 percent increase in the 95/50 ratio of incomes is associated with a 20 percent increase in the propensity of households earning more than $\$ 150,000$ to live downtown relative to the average household, and a 10 percent decrease in the corresponding propensity for households earning less than $\$ 40,000$. These cross-CBSA correlations suggest that shifts in the income distribution may be a quantitatively important factor in explaining the evolution of sorting by income from 1990 to 2014 shown in Figure 1, i.e., in explaining the relative urbanization of the rich and suburbanization of the poor. ${ }^{22}$

\footnotetext{
${ }^{22}$ Appendix Figure C.5 provides an alternative illustration of this cross-city variation: scatterplots showing that CBSAs with higher average and top income growth saw greater urbanization of high-, relative to low-, income
} 
Figure 2: Correlation between Change in Propensity to Live Downtown and Change in CBSA Income Distribution by Household Income between 1990 and 2014

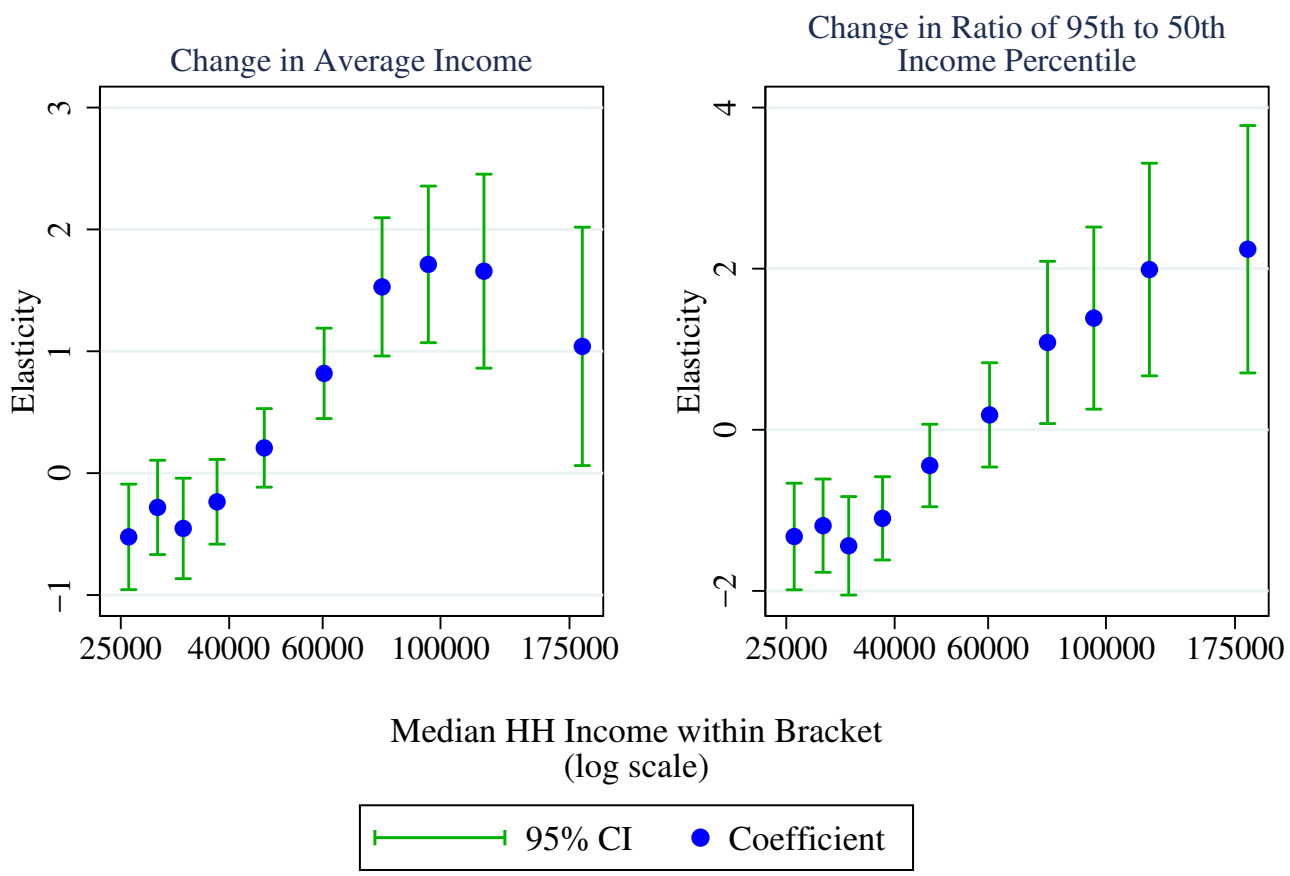

Note: This figure shows income bracket-specific coefficients, along with 95 percent confidence intervals, for regressions of the propensity of households in that income bracket to reside downtown in a CBSA against a measure of CBSA income growth. Each income bracket specific regression comes from exploiting cross-CBSA variation with observations weighted by CBSA population. The independent variable in the left panel is the change in average CBSA income while the independent variable in the right panel is the change in the ratio of the $95^{t h}$ to the the $50^{t h}$ percentile of household income in the CBSA. The y-axis shows the income bracket specific regression coefficients and the $\mathrm{x}$-axis shows median income within each income bracket. All changes are from 1990 to 2014.

\subsubsection{Model-Consistent Estimation}

The descriptive results above suggest that income growth and sorting by income are associated across CBSAs, but it still remains to show that this link is consistent with the mechanism proposed in section 2, and plausibly causal. We now fill this gap, testing the key sorting mechanism in the model with an instrumental variable strategy that addresses factors that confound the link between income growth and spatial re-sorting.

Estimating Equation Equation (7) in the model is key for what we do next. It shows that household location choice is a simple function of disposable income (income net of commute-adjusted housing prices). In particular, equation (7) implies that any changes in sorting by income are driven solely by changes in housing prices $p_{n j}$, i.e., by the higher willingness of richer households to pay the higher cost of locating in more attractive neighborhoods. Put differently, changes in house households. 
prices $p_{n j}$ capture all there is to know about how a change in the income distribution in the city will impact sorting. Our empirical strategy is therefore to measure how, across cities, changes in house prices, driven by changes in income growth, trigger spatial re-sorting by income. To do so, we derive the following estimating equation from (7), interpreting different time periods and different cities as different equilibria of the model and taking log differences across two time periods and two pairs of income groups $m$ and $m^{\prime}$ for each CBSA $c$ :

$$
\Delta \ln \left(\frac{\lambda_{D j, c}\left(w_{m}\right)}{\lambda_{S j, c}\left(w_{m}\right)}\right)-\Delta \ln \left(\frac{\lambda_{D j, c}\left(w_{m^{\prime}}\right)}{\lambda_{S j, c}\left(w_{m^{\prime}}\right)}\right)=\rho\left[\Delta \ln \left(\frac{w_{m}-p_{D j, c}^{h}}{w_{m}-p_{S j, c}^{h}}\right)-\Delta \ln \left(\frac{w_{m^{\prime}}-p_{D j, c}^{h}}{w_{m^{\prime}}-p_{S j, c}^{h}}\right)\right] .
$$

Normalizing brackets $m$ and $m^{\prime}$ such that $w_{m}>w_{m^{\prime}}$, the dependent variable is positive if the richer income bracket urbanizes faster than the poorer income bracket. The independent variable is positive when house prices rise faster downtown than in the suburbs. This results from the unit housing requirement: the same house price growth decreases the disposable income of the rich by a smaller percentage than that of the poor. Therefore, if the rich urbanize faster than the poor in response to house price growth downtown relative to the suburbs, then $\rho$ will be positive, consistent with the model. In contrast, if sorting patterns were unrelated to income, we would estimate $\rho=0$. Estimating (23) therefore provides a test of our income sorting mechanism. We now turn to estimating $(23) .{ }^{23}$

Identification Beyond the sorting mechanism that we aim to estimate, there may be other local shocks that drive both sorting and housing price growth across cities, confounding identification. Note that any local shocks that are valued equally by all incomes, or whose impact is captured by a switch in quality level $j$, will not compromise identification. These shocks are captured by $B_{n j}$ in the model and controlled for by differencing across income groups $m$ and $m^{\prime}$ within a quality tier in a CBSA. Similarly, income-specific shocks that affect the attractiveness of all neighborhood types in a CBSA uniformally will be controlled for by differencing between the downtown $D$ and suburban $S$ areas of each CBSA. To confound identification, shocks need to be both biased towards either downtown or the suburbs and income-specific, and not controlled for by our quality levels. Using the terminology of the model, such a shock would make the attractiveness of neighborhood of type $n j$ income specific, i.e., equal to $B_{n j}\left(w_{m}\right)$ instead of $B_{n j}$, thus introducing an error term into equation (23). Denoting the unobserved income-specific component of neighborhood attractiveness as $\epsilon_{n j}\left(w_{m}\right)=B_{n j}\left(w_{m}\right)-B_{n j}$, the error in equation (23) is equal to $\Delta \ln \left(\frac{\epsilon_{D j, c}\left(w_{m^{\prime}}\right)}{\epsilon_{S j, c}\left(w_{m^{\prime}}\right)}\right)-\Delta \ln \left(\frac{\epsilon_{D j, c}\left(w_{m}\right)}{\epsilon_{S j, c}\left(w_{m}\right)}\right)$. This error term will only be non-zero if demand shocks vary both by income and location within each city. Such shocks could include downtown-biased growth

\footnotetext{
${ }^{23}$ Without micro panel data we cannot observe how the location choice of a given household changes as their income $w$ changes. We instead estimate (23) using 45 distinct income-bracket pairs of $w_{m}$ and $w_{m^{\prime}}$ for each quality tier $j$. We pool our estimation across income pairs and organize the data such that $w_{m}>w_{m^{\prime}}$. As a result, the maximum number of observations in each of our regressions is 9000 , though in many specifications, we have less given missing data at the CBSA-area-quality triplet. We also remove any observation with $w-p_{c n j}^{h}<0$ (1.4\% of our sample). We then censor the top and bottom 1 percent of $\ln \left(\frac{w-p_{c D j}^{h}}{w-p_{c S j}^{h}}\right)$ in each year.
} 
in amenities by local city planners that are only valued by the high-skilled, like private schooling, luxury retail, or proximity to high-skilled jobs. If these factors make downtowns more attractive to high-income households and drive house prices up downtown relative to the suburbs, they would bias our estimate of the coefficient $\rho$ upwards.

To overcome this identification challenge, we use an instrumental variable strategy. We instrument for relative changes in house prices using an idea closely related to our theory. First note that the housing supply elasticity is lower downtown (both by assumption in our model and in the data per recent work by Baum-Snow and Han (2019)). So, CBSA-level income growth will generate more house price growth downtown than in the suburbs; we verify that this is the case empirically below. This suggests instrumenting the difference in house price growth between downtown and the suburbs in equation (23) using a plausibly exogenous CBSA-level income shock. We implement this idea using a shift-share (Bartik) shock to CBSA per capita income. The Bartik shock predicts the change in CBSA average earnings by projecting trends in industry-level average earnings observed elsewhere in the country on each CBSA's initial industry mix.

The exclusion restriction is that proposed in Borusyak et al. (2018): industry shocks need to be conditionally exogenous, in the sense that they are uncorrelated with the income- and downtownbiased error term described above. Specifically, we assume that industries that experienced higher national wage growth were not initially disproportionately located in CBSAs where downtowns gained skill-biased amenities relative to the suburbs.

This exclusion restriction may be violated if the industries that experienced higher national wage growth are themselves both downtown- and skill-biased. For example, if tech firms employ high-skilled individuals and are initially over-represented downtown, then national wage growth in tech could attract high income individuals downtown. To address this concern, we show that our results are robust to excluding various sets of industries that are either downtown- and/or skill-biased. First, we exclude the top quartile of downtown-biased industries from the computation of our Bartik shock. Specifically, we remove industries in which residents of urban areas are most likely to work. ${ }^{24}$ This isolates wage growth in suburbanized industries to instrument for relative house price growth downtown. Second, we recompute a Bartik instrument leaving out tech industries and then separately finance, insurance, and real estate (FIRE) industries. These industries disproportionately employ higher skilled workers. As we highlight below, all three alternative instruments yield similar results to our main instrument. We interpret this as further evidence, consistent with recent research, that access to jobs is not underlying the recent in-migration of high income individuals into urban centers.

Our exclusion restriction could still be violated if our Bartik instrument is larger specifically in CBSAs where industries that employ downtown residents experienced faster national wage growth than industries that employ suburban residents. To directly test for this, we calculate area-specific Bartik shocks by interacting national industry-level wage growth with CBSA-specific industry

\footnotetext{
${ }^{24}$ To do so, we first rank industries by the share of their workers that lives downtown. Then, starting from the industry with the most urbanized workers, we remove industries entirely from our Bartik computation until 25 percent of all workers have been removed.
} 
shares calculated first considering only workers who reside downtown, and second considering only workers who reside in the suburbs. ${ }^{25}$ We find that our baseline Bartik is almost perfectly correlated with the suburbs-only Bartik (correlation of more than 0.99), but less so with the downtown-only Bartik (correlation of 0.76). This is not surprising, given that the suburbs account for 90 percent of CBSA population. Moreover, our baseline Bartik is uncorrelated with the ratio between its downtown-specific and suburban-specific analogs. In other words, our Bartik shock is not larger in CBSAs where workers in high wage growth industries are initially over-represented downtown. Collectively, these results reassure us that the growth of industries that are located downtown and employ high income workers are not driving our identification of $\rho$.

Identifying Variation Before estimating $\rho$ using equation 23, we illustrate the variation in the data that allows for identification. We first verify that, in line with the logic above, the Bartik income shock raises house prices more downtown than in the suburbs. To illustrate this variation, we plot our Bartik shock between 1990 and 2014 for each CBSA (on the x-axis) against $\Delta \ln \left(p_{D j, c}^{h} / p_{S j, c}^{h}\right)$ (on the y-axis) in the left panel of Figure 3. There are 200 observations in the figure: 2 quality tiers within each of our 100 CBSAs. We find that within each quality tier, a more positive income shock raises housing prices downtown relative to the suburbs. This variation underlies the significant first-stage statistic in our estimation of $\rho$ below.

Next, we report the reduced-form regression of change in spatial sorting directly on the Bartik shock. To simplify the presentation, we pool quality tiers and show the results of the following regression for each of our 10 income brackets:

$$
\Delta \ln \left(\frac{\lambda_{D, c}(w) / \lambda_{D, c}}{\lambda_{S, c}(w) / \lambda_{S, c}}\right)=\alpha^{w}+\beta^{w} \Delta \widehat{\operatorname{Income}}_{c}{ }^{\text {Bartik }}+\nu_{c}^{w} .
$$

This regression is exactly the same as our descriptive regression (22), except that the Bartik income shock replaces actual income growth. In equation (24), $\beta^{w}>0$ implies that following a positive CBSA Bartik shock, the propensity of income group $w$ to live downtown rises relative to that of the average CBSA resident. The right panel of Figure 3 reports estimates from equation (24), along with their 95 percent confidence bounds. We find that a CBSA income shock causes differential spatial sorting responses from the rich vs. the poor. In particular, rich households are more likely than poor households to move downtown in response to an income shock. For all the top five income groups, $\beta^{m}>0$ and all estimates are statistically significant at the 5 percent level. Conversely, all the bottom five income groups have estimates of $\beta^{m}<0$, with all but the middle income group estimate being statistically significant. To summarize, Figure 3 provides reducedform evidence consistent with the key mechanism in our model. As CBSA income increases, house prices grow faster downtown, and richer households are more likely to re-sort downtown relative to poorer households.

\footnotetext{
${ }^{25}$ These computations are only possible in 27 CBSAs in which PUMAs are small enough to map into our downtown definition.
} 
Figure 3: Identifying Variation for $\rho$
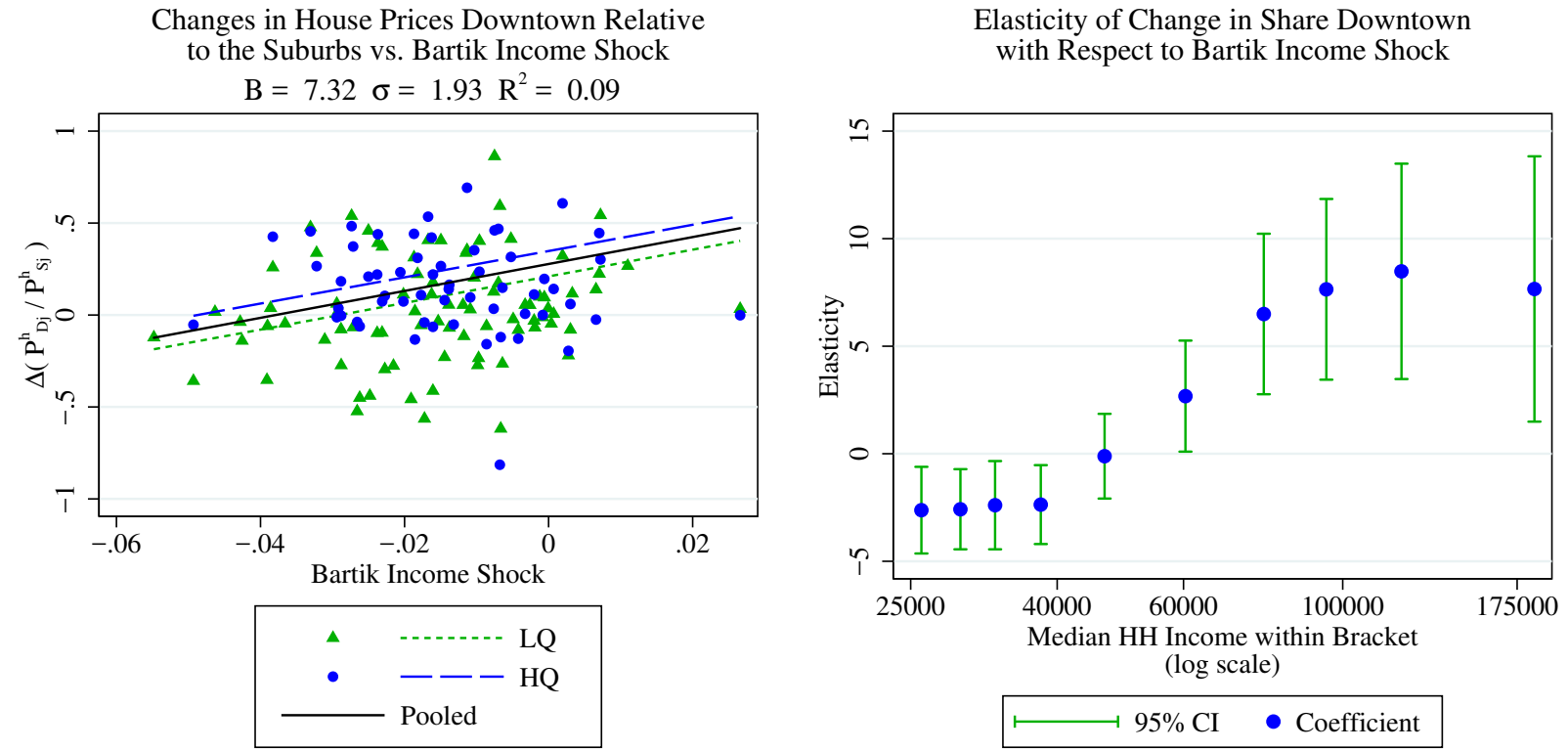

Note: On the left, we plot changes in downtown relative to suburban house prices within each quality tier on the y-axis, against the Bartik income shock between 1990 and 2014 on the x-axis for each of the largest 100 CBSAs. The house price data is from the Zillow 2 Bedroom Index in 1996-1998 and 2012-2016. We drop the top and bottom $1 \%$ of $\Delta\left(p_{D j}^{h} / p_{D j}^{h}\right)$ from the plot. On the right, we show income bracket-specific coefficients, along with 95 percent confidence intervals, from equation (24) on the y-axis (regression of Bartik income shock on changes in normalized urban share from 1990 to 2014), against median income within each income bracket on the x-axis. Both panels show CBSA population weighted regression coefficients

Estimates of $\rho$ Having clarified the variation that identifies (23), we are now ready to estimate $\rho$ - the parameter that governs the intensity of income-based sorting. Our baseline results are reported in the first two columns of Table 1. Column 1 shows an OLS estimate, and column 2 shows an IV estimate using the Bartik instrument. We weight both OLS and IV regressions by the number of observations in each cell. This downweights cells with fewer individuals where measurement error may be higher.

Our OLS estimate is somewhat lower than our IV estimate (2.34 vs. 3.07), but we cannot reject that they are the same. Our instrument has strong first stage predictive power with an F-stat of 23. Columns (3)-(5) show IV estimates for alternative Bartik shocks that exclude urbanized, FIRE, and Tech industries. These estimates are similar to our base results, ranging from 2.47 to 3.21. This suggests that our instrument is not correlated with labor demand shocks that are concentrated in urban centers of CBSAs and that disproportionately affect high income individuals. As an additional robustness exercise, we also estimated the regression 90 separate times - once for each possible $w_{m}-w_{m^{\prime}}$ income pair and for each quality level - instead of running the pooled regression (23). There, we find that our weighted median estimates of $\rho$ are similar to those above. Importantly, we find that these $m-m^{\prime}$-pair specific $\rho$ estimates are essentially uncorrelated with the difference in gross income between the $w_{m}-w_{m^{\prime}}$ pairs in the regression. This invariance is a test of the functional form assumptions embedded in the model. ${ }^{26}$

\footnotetext{
${ }^{26}$ Appendix C.5 shows further robustness of our estimates of $\rho$ to many different specifications, including different
} 
Table 1: Estimation of elasticity $\rho$

\begin{tabular}{|c|c|c|c|c|c|}
\hline & (1) & $(2)$ & (3) & (5) & (6) \\
\hline$\hat{\rho}$ & $\begin{array}{c}2.34 \\
(0.27)\end{array}$ & $\begin{array}{c}3.07 \\
(0.63)\end{array}$ & $\begin{array}{c}2.69 \\
(0.69)\end{array}$ & $\begin{array}{c}2.47 \\
(0.75)\end{array}$ & $\begin{array}{c}3.21 \\
(0.65)\end{array}$ \\
\hline Instrument & None & Base & $\begin{array}{c}\text { Omit } \\
\text { Top Urban } \\
\text { Industries }\end{array}$ & $\begin{array}{c}\text { Omit } \\
\text { FIRE } \\
\text { Industries }\end{array}$ & $\begin{array}{c}\text { Omit } \\
\text { Hi-Tech } \\
\text { Industries }\end{array}$ \\
\hline $\mathrm{R}^{2}$ & 0.24 & & & & \\
\hline KP F-Stat & & 23.1 & 16.7 & 14.8 & 16.5 \\
\hline Obs & 5,586 & 5,586 & 5,586 & 5,586 & 5,586 \\
\hline
\end{tabular}

Notes: This table shows estimates from equation (23). Data from 100 largest CBSAs where neighborhood quality defined from education mix of residents. Each observation is weighted by the number of households in the income bracket. Column 3 to 5 also control for share of omitted industries. Standard errors clustered at the CBSA-quality level are in parentheses. KP F-Stat $=$ Kleinberger-Papp Wald F statistic.

To summarize, we use our preferred IV estimate in column 2 and set $\rho=3.0$ in our model calibration. As we show later, $\rho$ is an important parameter determining our welfare results. In our counterfactual exercises we show the sensitivity of our results to alternate values of $\rho$ between 2 and 4 which encompass roughly the two standard deviation bands of our estimate in column 2 .

\subsection{Neighborhood Change}

Before moving on to our full model quantification, we highlight one additional reduced form relationship that is consistent with our model. In the model, changes in demand for locations are amplified by endogeneous neighborhood change. As high income households move downtown, neighborhoods with low quality amenities are replaced by neighborhoods with high quality amenities. Figure 4 shows that the typical downtown tract saw larger increases in neighborhood quality than the typical suburban tract, particularly in CBSAs that had larger Bartik income shocks. This is the case using either of our quality proxies. The left panel plots the percentage point growth in the population-weighted median tract college share downtown minus that for the suburbs against the Bartik income shock. This panel shows that downtowns became relatively more educated than the suburbs in response to CBSA income growth increases between 1990 and 2014. Likewise, the right panel plots the growth in the population-weighted median tract restaurant quality index downtown relative to the suburbs against the Bartik income shock. This figure shows that restaurant quality increased sharply downtown relative to the suburbs in response to CBSA income growth.

time periods, different house price measures, and different quality cut-offs. These robustness estimates are all within two standard error bands of our preferred estimate. Finally, we also note that we implemented the corrected shiftshare IV standard errors as suggested in Adão et al. (2018). These standard errors are derived under the identifying assumption that we make here, which is that industry shocks are conditionally exogenous. We find that all coefficients remain significant at the $1 \%$ level. 
Figure 4: Difference in Amenity Quality Growth between Downtown and the Suburbs Across CBSAs with Different Aggregate Bartik Income Shocks
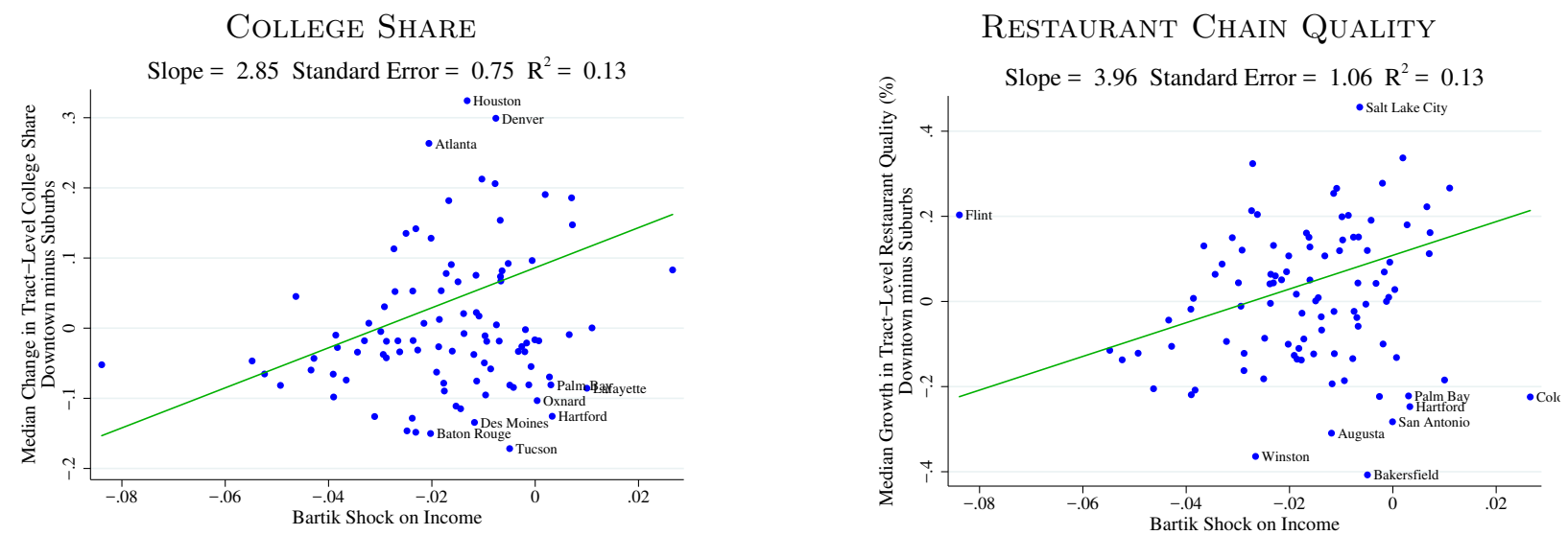

Note: These figures plot the difference in the change in the median quality of tracts downtown between 1990 and 2014 and the median quality of tracts in the suburbs over the same period across CBSAs. This quality growth differential is plotted against CBSA-level Bartik income shocks over the same period for the largest 100 CBSAs in 1990 . On the x-axis of each plot is the Bartik income shock from 1990 to 2014 . In the left plot, tract quality growth in an area (downtown or the suburbs) is measured as the absolute change in the population-weighted median college share across tracts in that area. In the right plot, tract quality growth in an area is measured as the percent change in the population-weighted median restaurant chain quality index - as described in section 3.1 - across tracts in the area. The line through each scatterplot shows the CBSA-population weighted linear fit.

The association between large income growth and outsized quality growth downtown relative to the suburbs is driven, for the most part, by absolute quality growth downtown. Collectively, these results highlight that CBSAs with more income growth saw more amenity improvements downtown than in the suburbs, as predicted by our model.

\section{$4 \quad$ Model Quantification}

Having established the empirical relevance of the key model mechanism and provided a micro-based estimate of $\rho$, we now turn to quantifying the remaining structural parameters of the model. We do so in two stages. In a first stage, we estimate key model elasticities and calibrate others. In a second stage, we use the method of moments to calibrate the remaining parameters of the model. We refer the reader to Appendix D for the full details of the procedure.

\subsection{Model Parametrization}

Table 2 lists the twelve elasticities we estimate (including $\rho$ ). We discuss the selection of each parameter briefly here. The role played by these parameters in driving sorting patterns and welfare results are discussed in detail in section 5. All of the parameters selected here are for our baseline calibration. We explore robustness over a range of values for each parameter in section 6.3.

Demand Parameters $(\gamma, \alpha, \delta$, and $\sigma$ ) Income sorting (governed by $\rho$ ) is amplified in the model by endogenous neighborhood development. The intensity of this effect is governed by the shape 
Table 2: Key Model Parameters

\begin{tabular}{|c|c|c|c|}
\hline Parameter & Description & Value & Source \\
\hline \multicolumn{4}{|c|}{ Non-homotheticity } \\
\hline$\rho$ & Between-type neighborhood substitution elasticity & 3.0 & Estimation \\
\hline \multicolumn{4}{|c|}{ Land Price Responses } \\
\hline$\epsilon_{D}$ & Downtown land supply elasticity & 0.6 & Calibrated to Saiz (2010) \\
\hline$\epsilon_{S}$ & Suburban land supply elasticity & 1.3 & Calibrated to Saiz (2010) \\
\hline \multicolumn{4}{|c|}{ Amplification } \\
\hline$\gamma$ & Within-type neighborhood substitution elasticity & 6.5 & Assumption $=\sigma$ \\
\hline$\alpha$ & Amenity share & 0.15 & CEX \\
\hline$\sigma$ & Substitution elasticity across neighborhoods & 6.5 & Estimation+literature \\
\hline$\delta$ & Distance elasticity across neighborhoods & 0.2 & Estimation+literature \\
\hline \multicolumn{4}{|l|}{ Other } \\
\hline$T_{D}$ & Downtown local property tax & 0.2 & IPUMS 2000 \\
\hline$T_{S}$ & Suburban local property tax & 0.3 & IPUMS 2000 \\
\hline$\Omega$ & Public amenity supply elasticity & 0.05 & Literature \\
\hline$\tau_{D}^{C}$ & Commute costs as share of labor income downtown & 0.044 & Authors' calculation \\
\hline$\tau_{S}^{C}$ & Commute costs as share of labor income suburbs & 0.059 & Authors' calculation \\
\hline
\end{tabular}

parameter $\gamma$, which controls gains from variety in residential neighborhood choice. For our baseline calibration, we set $\gamma=6.5$, a conservative upper bound equal to the elasticity of substitution for consumption amenities $(\sigma)$ that we estimate below. ${ }^{27}$

The parameters $\alpha, \delta$, and $\sigma$ govern demand for consumption amenities that households can visit - they correspond to the full specification of the model discussed in section 2.3. We parameterize $\alpha$, the share of net disposable income spent on non-tradable consumption amenities, using CEX expenditure data. We estimate the product of $\sigma$, the elasticity of substitution that governs gains from consumption amenity variety, and $\delta$, the cost of travel distance, using a gravity equation for amenity consumption in different neighborhoods of the city. We estimate this gravity regression, derived directly from the model, using the smartphone data introduced in section 3 . The richness of the smartphone data allows us to make three important provisions to help with identification in an otherwise standard gravity approach. First, we keep only visits to venues that match our model notion of non-tradable consumption amenities. Second, we add tract origin and destination fixed-effects to control for unobserved amenity price and quality, which would be impossible using sparse travel surveys. Third, we can limit our attention to visits that start from home and come directly back home, to control for many unobserved determinants of venue choice, such as a venue being on ones way to work. This gravity estimation yields $\widehat{\sigma \delta}=1.3$. We also find a $\delta$ around 0.2

\footnotetext{
${ }^{27}$ Existing research suggests that there is less socio-economic diversity within census tracts than there is within retail establishments such as grocery stores and restaurants. In the context of our model, this suggests that the substitution elasticity for residential amenities $(\sigma)$ is an upper bound for $\gamma$.
} 
using data on restaurant travel costs and meal prices from Couture (2016) and so recover $\hat{\sigma}=6.5$, which reassuringly stands midway in the range of values for similar elasticities from the existing literature. ${ }^{28}$ See Appendix D for further details on the estimation of these parameters.

Land Supply Elasticities ( $\epsilon_{S}$ and $\epsilon_{D}$ ) In the model, the area-specific elasticity of land supply $\left(\epsilon_{n}\right)$ directly translates into an elasticity of housing supply. We calibrate $\epsilon_{D}$ and $\epsilon_{S}$ to match the Saiz (2010) housing supply elasticity estimates for cities that have an average household density similar to that in our representative downtown and suburban areas. This yields $\hat{\epsilon}_{D}=0.60$ and $\hat{\epsilon}_{S}=1.33 .^{29}$ These numbers are conservative relative to the supply elasticities estimated in Baum-Snow and Han (2019) for the center and periphery of the city. ${ }^{30}$

Commuting Costs $\left(\tau_{S}\right.$ and $\left.\tau_{D}\right)$ We estimate the area-specific commuting cost $\left(\tau_{n}\right)$ with data on trip time to work by car from the geo-coded 2009 National Household Travel Survey combined with estimates of the value of commuting time from the meta-analysis in Small et al. (2007). This yields baseline values of $\tau_{D}=0.044$ and $\tau_{S}=0.059$.

Trip Share to Amenities $\left(S_{n j}^{m k}\right)$ Expenditure shares $S_{n j}^{m k}$ defined in (18) measure the share of amenity consumption spent in neighborhoods of type $m k$ for a household living in a neighborhood of type $n j$. We proxy for these share with the corresponding trip shares reported in Table 3 that we read directly from the same smartphone data used to estimate demand for consumption amenities.

Public Amenities $\left(T_{D}, T_{S}, \Omega\right)$ We calibrate local taxes $\left(T_{n}\right)$ to match the unit-level average real estate taxes paid as a share of annualized housing costs in 2000, using tract-level data from the 2000 Census. This implies a local property tax rate as a fraction of the annual user cost of housing of $30 \%$ in the suburbs and $20 \%$ downtown. We set the elasticity of the endogenous component of the public amenity with respect to these tax revenues $(\Omega)$ to 0.05 (Fajgelbaum et al., 2018).

Homeownership $(\chi(w))$ In our benchmark model, we assume that all housing rents in the city (land rents and fixed costs of development) accrue to an absentee landlord and none are transferred to the city residents, i.e., that $\chi(w)=0$ for all $w$. In our counterfactual analysis, however, we want to be able to account for the heterogeneous rate of home ownership in contributing to spatial

\footnotetext{
${ }^{28}$ Atkin et al. (2018) find an elasticity of substitution of 3.9 for retail stores in Mexico, Einav et al. (2019) find 6.1 for offline stores in the U.S., Su (2018a) and Couture (2016) find 7.5 and 8.8 respectively for restaurants in the U.S.

${ }^{29}$ In our downtowns, the average CBSA population-weighted household density is 4,300 households per square mile, versus 300 in the suburbs. The highest density CBSA, New York, has 850 households per square mile, so the average density in $D$ is out-of-sample. However, $\hat{\epsilon}_{D}=0.60$ turns out to equal the elasticity of housing supply in Miami, which is the metropolitan area with the most inelastic housing supply in Saiz (2010).

${ }^{30}$ Baum-Snow and Han (2019) estimate tract-specific indexes with an interquartile range of 0.46-1.12 using a repeated sales price index and 0.99-1.59 using a hedonic index. They also estimate a representative supply elasticity as a function of distance which implies a supply elasticity of $0.21(0.35)$ at the city center and $1.43(0.86)$ at the periphery using the repeat sales (hedonic) price index. Our estimates imply that, if anything, we overestimate the elasticity of supply downtown and underestimate the difference in the elasticity of supply between downtown and the suburbs. Robustness checks in Appendix E show that both biases will lead us to underestimate both the degree of sorting that result from top income growth and the associated welfare effects.
} 
Table 3: Non-tradable Trip Shares

\begin{tabular}{|c|c|c|c|c|c|}
\hline & \multicolumn{4}{|c|}{ Destination } \\
\hline & & $\mathrm{DL}$ & $\mathrm{DH}$ & $\mathrm{SL}$ & $\mathrm{SH}$ \\
\hline \multirow{4}{*}{ 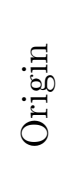 } & DL & 0.61 & 0.20 & 0.12 & 0.07 \\
\hline & $\mathrm{DH}$ & 0.07 & 0.82 & 0.03 & 0.08 \\
\hline & SL & 0.02 & 0.03 & 0.78 & 0.17 \\
\hline & $\mathrm{SH}$ & 0.01 & 0.03 & 0.19 & 0.77 \\
\hline
\end{tabular}

Notes: This table shows the share of trips observed in the smartphone data to non-tradable services in neighborhoods of each quality-area type. Each row shows the allocation of trips for individuals that live in neighborhoods of each quality-area type. Appendix $\mathrm{C}$ defines the non-tradable services included and provides further details on this data source.

sorting responses, in order to allow households who own their home to reap the benefits of rising house prices. To do so, we discipline $\chi(w)$ by transferring to households at each labor income level capital gains corresponding to their average real estate portfolio. This transfer equals the average house price growth in the neighborhoods where households of that income lived in the previous period, which is then scaled by the share of households who were homeowners according to the 2000 IPUMS data. Empirically, this share of home ownership increases systematically with labor income.

\subsection{Second Stage: Method of Moments}

Armed with estimates for the key elasticities of the model, we conclude the calibration of the model using a method of moments. We set the remaining parameters that govern neighborhood rents and attractiveness to levels which, conditional on the model elasticities, minimize the distance between the model moments and their empirical counterparts.

This method of moments allows us to estimate two key vectors of composite model parameters: (i) the relative attractiveness of each neighborhood type $\left\{\tilde{B}_{n j}\right\}_{n j}$, and (ii) the price of housing in each neighborhood type $\left\{p_{n j}^{h}\right\}_{n j}$, which together pin down the calibrated values for location choices $\left\{\lambda_{n j}(w)\right\}_{n j}$ at all levels of income $w$ in the baseline equilibrium. The procedure does not separately identify all of the structural parameters of the model that shape these composites. But these composite parameters are just sufficient to compute any counterfactual equilibrium of the model, as we explain below.

We target two sets of moments that summarize the key economic concepts we aim to capture: (i) the 1990 distribution, by income level, of the share of workers living downtown (i.e., the U-shape presented in the introduction), and (ii) the median 1990 house price by neighborhood type (as used in the estimation of $\rho$ ). To accurately capture the location choices of higher-income households, we target the downtown share of households at a finer income grid than the Census income brackets represented in the introduction. To this end, we construct the same plot as Figure 1 but for finer $\$ 5,000$ income brackets (in 1999 dollars) using the micro IPUMS data. The additional detail in the 
income dimension comes at the expense of precision in the spatial dimension and, as a result, we are limited to studying 27 CBSAs of our original 100 in the calibration and counterfactual exercises. ${ }^{31}$ We perform this calibration and counterfactuals for a representative city that is an average of these 27 CBSAs. The U-shape patterns of residential sorting for these 27 CBSAs are very similar to the U-shape patterns documented in Figure 1.

The identification of the model in this second stage is quite straightforward. First, it is clear how the house price moments directly inform the calibration of $p_{n, j}^{h}$. Then, conditional on prices, the U-shape pattern of the location choice data helps identify the relative attractiveness $\tilde{B}_{n j}$ of different types of neighborhoods. This is a quite intuitive revealed preference approach, applied to our non-homothetic demand function: the same level of price and quality of a neighborhood generates different demand patterns at different levels of income. Concretely, the identification relies on the set of location choice equations for all income levels $w$ :

$$
\frac{\lambda_{D}(w)}{\lambda_{S}(w)}=\frac{\sum_{j=L, H} \tilde{B}_{D, j}^{\rho}\left[w-p_{D, j}^{h} /\left(1-\tau_{D}\right)\right]^{\rho}}{\sum_{j=L, H} \tilde{B}_{S, j}^{\rho}\left[w-p_{S, j}^{h} /\left(1-\tau_{S}\right)\right]^{\rho}}
$$

Given $\tau_{n}$ and $w$, the calibration backs out the $\tilde{B}_{n, j}$ and $p_{n, j}^{h}$ that allow to best match the distribution of location choices in the data. The vectors $\tilde{B}_{n, j}$ are pinned down up to a normalization level, whose value does not impact the counterfactuals done in the following section.

Moment Fit. The moment fit is presented in Figure 5. Since the model is over-identified, the price moment cannot be matched perfectly. Depending on the weight put on the price and location choice moments, the procedure trades-off a better fit of the U-shape for location choices against a better fit for housing prices. Despite a sparse specification, the calibrated model is able to match the rich non-monotonic U-shape patterns of location choice by households of various incomes remarkably well. The model also matches the relative housing prices in the suburbs quite well. In 1990, both the model and data have house prices in low quality downtown neighborhoods being roughly equal to low quality suburban neighborhoods. Likewise, both the model and data have high quality suburban neighborhoods having housing prices being about 40 percent higher than low quality neighborhoods. The model has a harder time matching the high quality housing prices downtown, and calls for higher prices in high quality downtown neighborhoods than those in the data. Both in the model and the data though, the highest price option is a downtown high quality neighborhood. ${ }^{32}$

\footnotetext{
${ }^{31}$ The IPUMS data identifies the locations of respondents at the PUMA (Public Use Microdata Area), each of which contains approximately 100,000 individuals, relative to the 4,000 contained in each Census tract. To replicate the urban share for each fine income brackets, we first construct a cross-walk between PUMAs and our tract-based downtown areas. There are 27 CBSAs in which PUMAs are small enough relative to the downtown definition so as to allow for useful inference here. See Appendix C for more details.

${ }^{32} \mathrm{~A}$ calibration of the model with three quality layers produces similar welfare effects, without significant improvements in the fit of either the U-shape or relative price moments. The high predicted cost of $D H$ neighborhoods relative to the cost of housing in the data might reflect that having a high quality standard of living downtown requires paying for housing as well as private schooling (whereas a similar standard of schooling in the suburbs is
} 
Figure 5: Calibration to 1990 Urban Shares and Neighborhood Prices
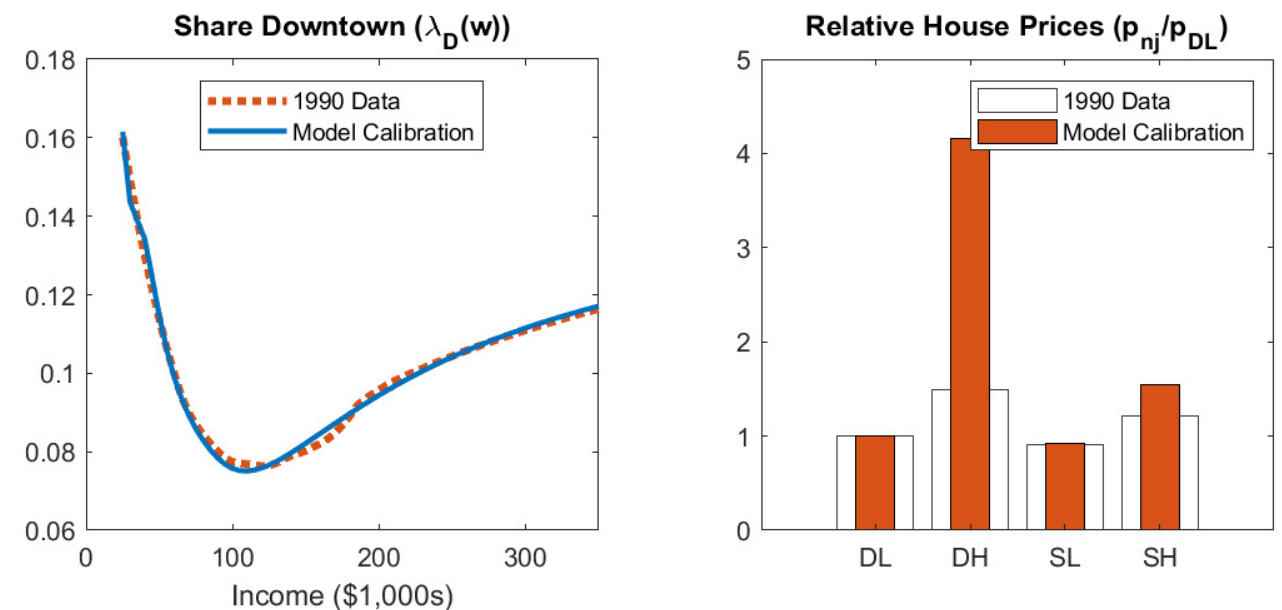

Notes: These figures show the fit of the calibrated model to the two targeted moments. The left-hand plot shows the share of households in each $\$ 5,000$ income bracket that reside downtown in 1990 . The dashed line shows the data, while the solid line shows the prediction of the calibrated model. The data are constructed from micro IPUMS data and reflect the propensity to reside downtown by income in the 27 CBSAs in which PUMAs (the finest spatial unit the IPUMS data) are small enough relative to the downtown definition to make useful inference here. The curve is interpolated to address top-coding in the IPUMS data. See Appendix C for more details. The clear bars in the right-hand plot shows the average Zillow 2 Bedroom Home Value Index in tracts of each location-quality type, normalized by the average index in low-quality tracts downtown, in 1996. The solid red bars show the predicted relative housing costs predicted by the calibrated model.

Figure 6 shows that the Engel curve in housing, a non-targeted moment implied by the calibrated model, does quite well at matching the relationship between housing expenditure and income in the 2014 CEX. In the model, the unit housing requirement means that, within-neighborhood type, all households spend the same amount on housing regardless of income, so the income share of housing expenditure is mechanically downward sloping in income. This slope is mitigated by non-homothetic sorting across neighborhoods: higher incomes sort into the more expensive neighborhood types so their income share of housing does not fall proportionally with income. See Appendix B.1 for additional discussion. With only four neighborhood types in the quantified model, this sorting goes a long way in replicating the income share of housing in the data.

\section{Income Growth and Changing Spatial Sorting}

Armed with our quantified model, we now turn to our main question of interest. Using counterfactual analysis, we gauge the extent to which a change in the income distribution in the city $(L(w))$ can help rationalize the observed changes in spatial sorting within the city. We start by analyzing the 1990-2014 period before turning to 1970-1990. In the next section, we investigate the welfare consequences of this spatial sorting.

often part of the public amenities and covered by property taxes and housing costs). 
Figure 6: Housing Expenditure Share by Income

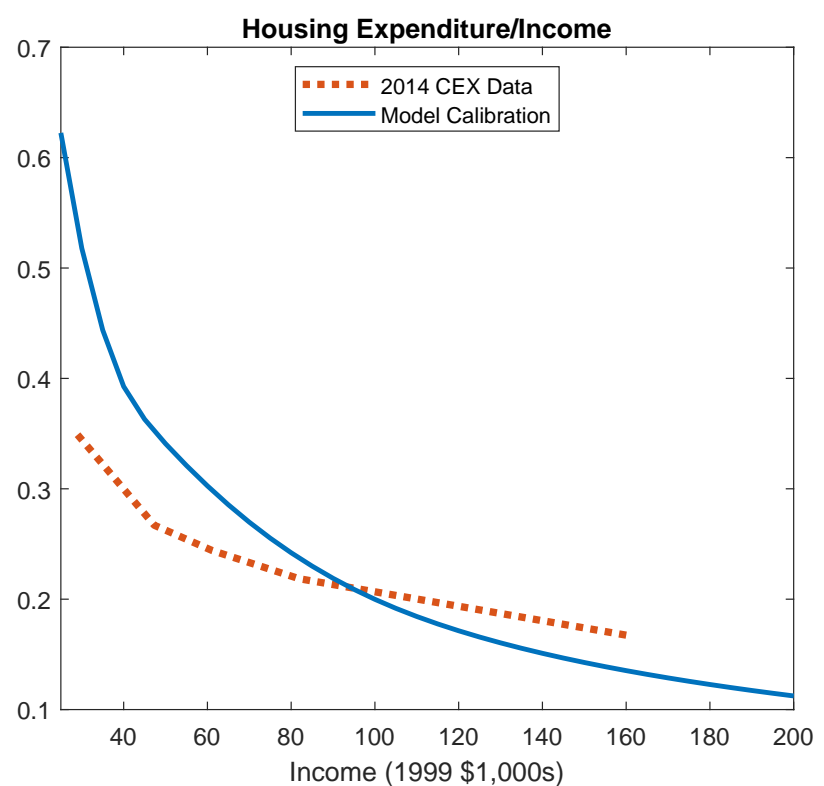

Notes: This figure shows both the model implied relationship between share of income allocated to housing (solid line) and the corresponding data from the Consumer Expenditure Survey in 2014 (dashed line). In published tables, the CEX reports average household income and average expenditure on shelter for each household income decile. The earliest year that the CEX reported average expenditures by income decile was 2014. The CEX line includes only eight data points, one for each decile where decile income exceeded $\$ 25,000$.

\subsection{Computing Counterfactuals}

To compute the counterfactual equilibria of the model that we are interested in, we use a logic similar to Dekle et al. (2007). Given the structure of the model, any counterfactual equilibrium - for instance one that is based on a different distribution of incomes $L(w)$ in the city - can be computed with the following parameters on hand: (i) the model elasticities $\left\{\rho, \gamma, \epsilon_{n}, \sigma, \alpha, \tau_{n}\right\}$, and (ii) the initial equilibrium values for population in each neighborhood type, house prices, and amenity trip shares $\left(\left\{\lambda_{n, j}(w), p_{n, j}^{h}, S_{n j}^{m k}\right\}\right)$ as calibrated above. Details of the procedure as well as the corresponding set of equations are given in Appendix B.

\subsection{Baseline counterfactual: 1990-2014 change in income distribution}

Between 1990 and 2014, the income distribution of the largest CBSAs became more unequal, mirroring the patterns documented for the economy as a whole. Panel A of Figure 7 summarizes this change plotting the percentage change in income between 1990 and 2014 for each income decile in the representative city made of 27 large CBSAs that we used to calibrate the model above. Income per capita grew on average by $10 \%$. For the bottom decile, however, income actually fell slightly by approximately 1 percent, while for the top decile, income increased by about 18 percent. Overall, the 90-10 income gap widened by 19 percentage points.

How much did this change in income distribution, in isolation, contribute to changes in spatial sorting within cities? We use the quantified model to answer this question. We compute the coun- 
Figure 7: Counterfactual change in sorting from shift in income distribution

Panel A: Change in Income Distribution

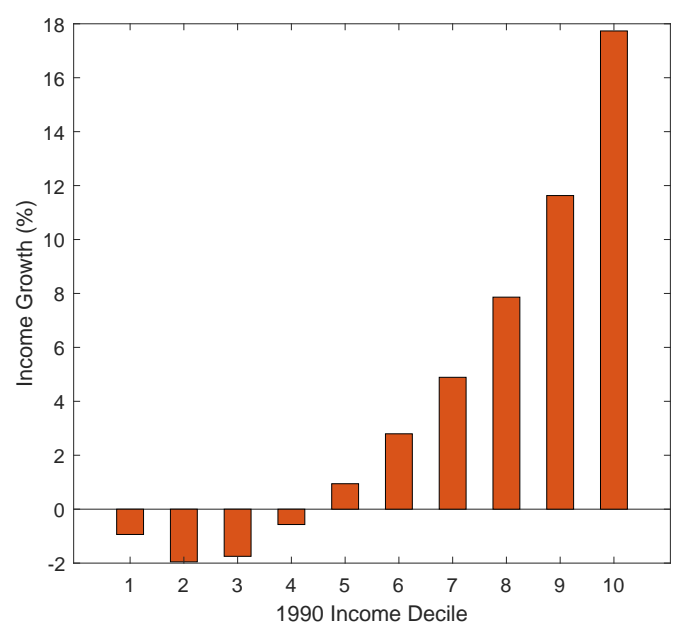

Panel B: Change in Share Living DownTown

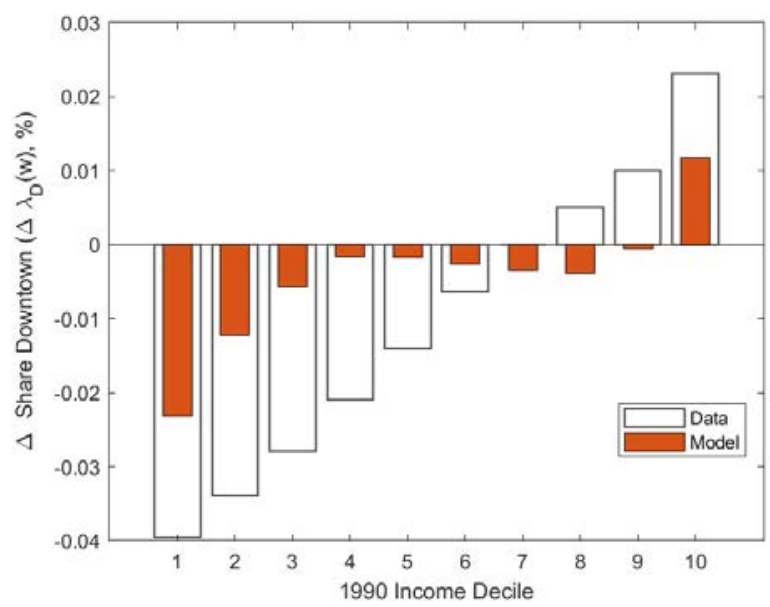

Notes: Panel A shows income growth between 1990 and 2014 by income decile for the 27 CBSAs used to calibrate our model. This panel summarizes the shift in the income distribution that we feed into the model. Panel B shows the change in the propensity to live downtown resulting from the change in the income distribution by income decile (solid red bars). The clear bars show the change in the propensity to live downtown between 1990 and 2014 by income decile in the data.

terfactual spatial equilibrium that corresponds to the 2014 income distribution, without changing any other parameters of the model. We then compare sorting in this model-based counterfactual to that in the actual spatial equilibrium in 2014. In Panel B of Figure 7, the clear wide bars show the actual change in the propensity to live in downtown areas between 1990 and 2014 for each decile of the income distribution, summarizing the shift in the U-shape of Figure 1. The skinnier solid red bars show the changes implied by the model.

In the model, the 1990-2014 change in the income distribution generates a shift in location choices that matches the general trend we observe in the data. High income households move downtown, while low income households move out of downtown. The predictive power of the income shock alone is substantive: it explains about 60 percent of the suburbanization of the bottom decile of the income distribution, and about half of the urbanization of the top income decile. The income shock does less well at explaining the changing location choices of individuals in middle income deciles. This suggests that factors aside from the changing income distribution are also quantitatively important in determining the changing location choices of residents of large cities. $^{33}$

\footnotetext{
${ }^{33}$ Note that the predicted urbanization of the highest income decile reflects both a shift along the calibrated Ushape of Figure 5 as well as an endogenous uptick in the U-shape, generated by the change in the income distribution. Appendix Figure E.6 shows that the model also explains a significant portion of the observed uptick itself.
} 


\subsection{Tests of Model Predictions}

Before analyzing how changes in spatial sorting patterns affect the welfare of different income groups, it is worth exploring whether our model predicts changes in spatial sorting in other settings beyond our baseline exercise. We perform two such validation exercises. First, we go further back in time from 1990 to 1970 and ask whether shifts in the income distribution can speak to changes in spatial sorting patterns during this earlier period, as it does in our 1990-2014 baseline counterfactual. Second, we replicate our baseline calibration and 1990-2014 counterfactual one-byone for each of the CBSAs that make up the representative city in our baseline analysis and use the results to study whether the model can reproduce salient differences in spatial sorting across CBSAs from 1990 to 2014.

\subsubsection{Predictions Going Backwards in Time: 1970 Counterfactual}

In this exercise, we feed the 1970 income distribution into the baseline model, originally calibrated to 1990. The top panel of Figure 8 shows that incomes unambiguously grew between 1970 and 1990. The lower panel of Figure 8, meanwhile, shows that this income growth generated very little change in sorting through the lens of the model. This result reflects that income growth is not a sufficient condition to cause high income households to disproportionately move downtown. What generates the change in sorting patterns in response to the income growth between 1990 and 2014 is specifically the increase in the number of households with very high income, far to the right of the bottom of our U-shape.

The 1970-1990 shift in the income distribution was much less skewed towards the very rich than the 1990-2014 shift. In fact, the largest income growth corresponded to income deciles around the bottom of the U-shape (around $\$ 100,000$ ), i.e., households that tend to be over-represented in the suburbs. In this income range, the model predicts that households move along their residential Engel curve by moving from low to high quality neighborhoods within the suburbs, barely impacting the relative share of households downtown.

The lower panel of Figure 8 shows that the lack of re-sorting predicted by the model in response to the income changes between 1970 and 1990 mimics the stability of the U-shape pattern over this period in the data (also depicted in Figure 1). ${ }^{34}$ If anything, the model correctly predicts the reverse of what we observed between 1990 and 2014: relative to the average household, those at the very right tail of the income distribution surburbanized between 1970 and 1990, while those at the left tail urbanized. These results show that the model can successfully predict different dynamics of changes in spatial sorting patterns, depending on where in the income distribution income growth takes place.

\footnotetext{
${ }^{34}$ The lower panel of Figure 8 displays normalized U-shape patterns - the propensity of a given income group to reside downtown relative to the average person. Between 1970 and 1990, all income groups became more suburbanized meaning there was a level shift up in the non-normalized U-shape in 1970. While our model misses the general suburbanization trend which is likely due to population growth (which we are holding fixed), it matches the differences across income groups very well.
} 
Figure 8: 1970 Counterfactual
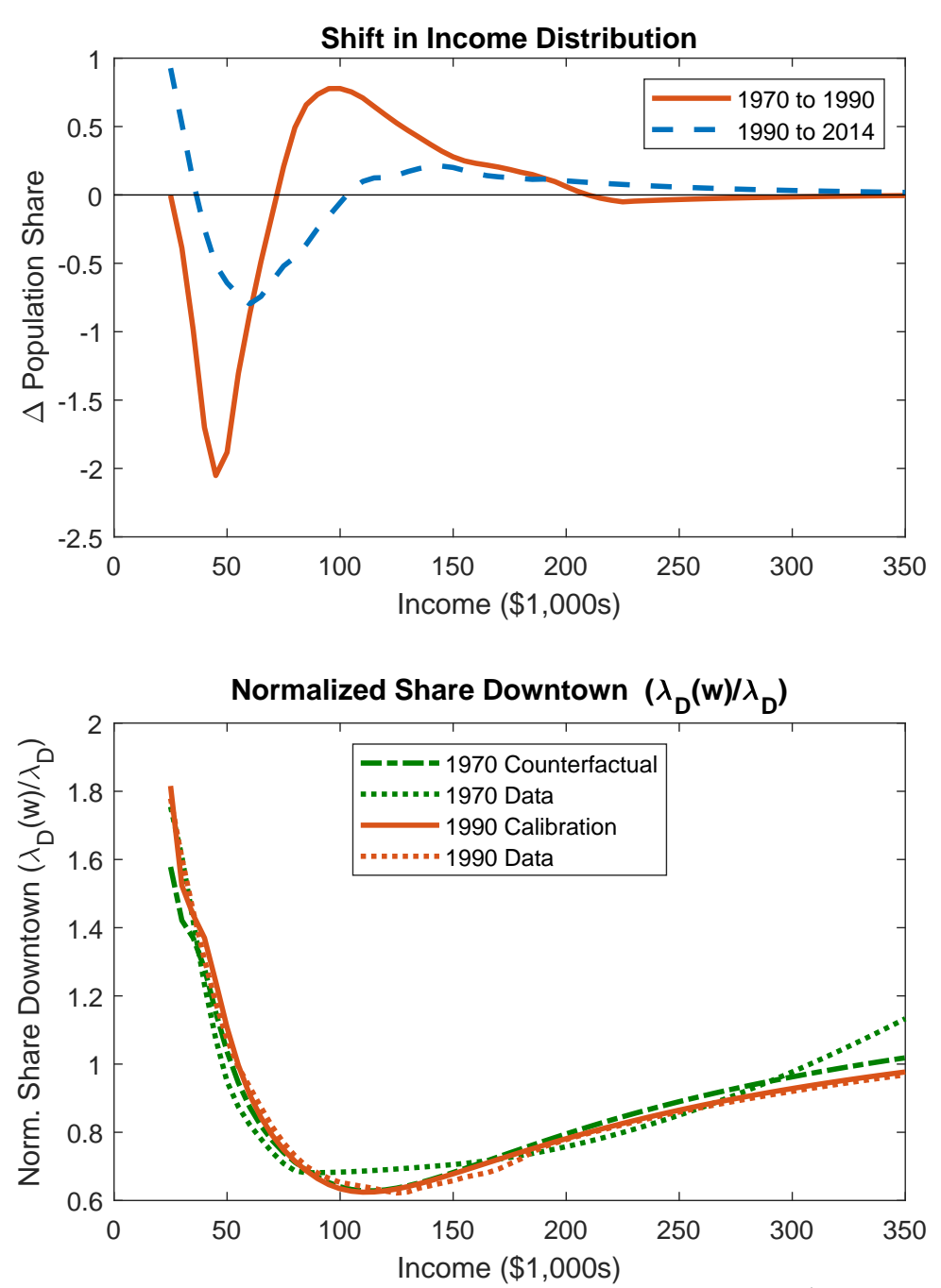

Notes: The top panel shows the percent change in the population share at each $\$ 5,000$ income bracket in the 27 CBSAs modeled in our calibration between 1970 and 1990 (solid) and 1990 and 2014 (dashed). The lower panel shows the share of each income bracket that resides downtown relative to the mean propensity to reside downtown in these CBSAs. The dotted curves show the data for 1970 (green) and 1990 (orange), while the dashed curve shows the predicted sorting in the 1970 counterfactual and the solid curve shows the predicted sorting in the 1990 calibration.

\subsubsection{Cross-CBSA Predictions}

As a second validation exercise, we assess whether the model can match the salient heterogeneity in the changes in residential sorting patterns across cities. To that end, we re-calibrate the model separately for individual CBSAs (rather than for a representative city as in the baseline). We allow CBSAs to differ from each other in their initial 1990 income distribution and initial spatial sorting patterns, in the change in their income distribution between 1990 and 2014, and in their land supply elasticities $\left(\epsilon_{D}\right.$ and $\left.\epsilon_{S}\right)$. The other parameters in Table 2 are assumed to be identical across CBSAs. For each CBSA, we calibrate the model by targeting the 1990 distribution of location choice by income within the CBSA, and then compute the model's prediction for how the CBSA's 
spatial sorting patterns change in response to the actual change in the CBSA income distribution. We then compare the predictions of the model to the empirical changes in residential sorting within each city.

Figure 9 compares the cross-CBSA heterogeneity in spatial sorting predicted by the model with that observed in the data using a simple summary statistic: the propensity of households with incomes higher than $\$ 100,000$ to reside downtown relative to the average household. The left hand panel of Figure 9 compares this statistic in the model to that in the data for each CBSA in $1990 .{ }^{35}$ Given that we target the U-shape in 1990 city by city, it is not surprising that our model matches the 1990 data so well. Our key result is shown in the right-hand panel of Figure 9. The plot compares the change in the share of households with incomes above $\$ 100,000$ that reside downtown between 1990 and 2014 in the data to the corresponding change predicted by the model in response to the CBSA-specific shock to the income distribution over the same time period. The results show that, through the lens of the model, CBSA-level changes in the income distribution explain CBSA-level changes in spatial sorting of high income individuals quite well. The CBSAs predicted by the model to have a large relative increase in high income individuals residing downtown are actually the ones where we observe such an increase empirically.

Figure 9: Urban Share of Households Earning Above \$70,000 Less the Average Urban Share
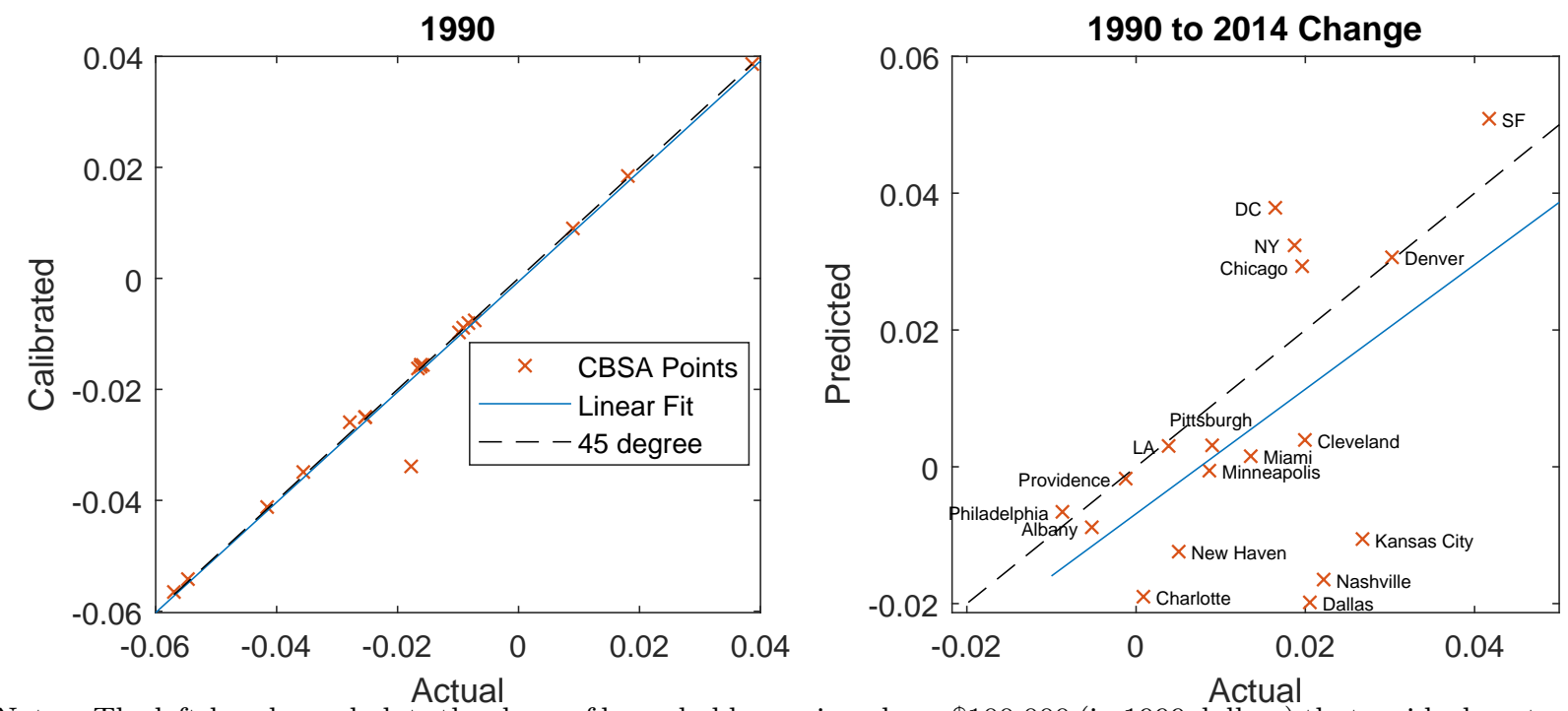

Notes: The left-hand panel plots the share of households earning above $\$ 100,000$ (in 1999 dollars) that reside downtown as predicted by the 1990 calibration for each CBSA vs. as observed in the 1990 data for each CBSA. The right-hand panel compares the change in this variable between the 1990 calibration and as predicted in the 2014 counterfactual for each CBSA vs. the CBSA-level change observed in the data over the same period.

We conclude from these out of sample analyses that the model does quite well at matching time series changes for a representative CBSA as well as cross-CBSA heterogeneity. We view this as a strong test of the model's implications linking the growth in income at the top of the

\footnotetext{
${ }^{35}$ For this analysis, we can only use 18 of 27 CBSAs. These are the CBSAs for which there is sufficient coverage above the state-specific IPUMS income topcodes to implement the generalized Pareto interpolation procedure that we use to measure CBSA-level income distributions and U-shapes, as described in Appendix C.
} 
income distribution with the influx of the rich into downtown neighborhoods within a CBSA. Many national stories that could be confounding our baseline results get differenced out in this cross-CBSA analysis. Likewise, the fact that the model also does well in explaining the lack of changing spatial sorting responses by income between 1970 and 1990 in response to the 1970-1990 income change also gives us confidence that the calibrated model can capture salient features from the data.

\section{$6 \quad$ Welfare and Policy Implications}

Having established the model's ability to reproduce salient empirical sorting patterns, we turn to using the model to analyze the normative implications of changes in urban spatial sorting. We first use the model to assess the well-being consequences, for different income groups, of the neighborhood change and spatial re-sorting triggered by top income growth between 1990 and 2014 . In doing so, we highlight the economic forces within the model that drive welfare differences across groups. We end this section by discussing the effectiveness of policies aimed at mitigating these changes in spatial sorting.

\subsection{Changes in Welfare Inequality}

The framework in section 2 delivers the following function for the representative utility of a household with income $w$ :

$$
V(w)=\left(\sum_{n^{\prime}, j^{\prime}} V_{n^{\prime}, j^{\prime}}^{\rho}(w)\right)^{1 / \rho}
$$

where $V_{n j}$ is the inclusive value of all neighborhoods of type $(n, j)$ defined above in (4). We use a related dollar-denominated measure to quantify the change in welfare between 1990 and 2014 by income decile, using compensating variation as follows:

$$
C V(i)=m_{2}(i)-m_{2}\left(V_{2}^{-1}\left(V_{1}\left(m_{1}(i)\right)\right)\right)
$$

where $m_{t}(i)$ is income of percentile $i$ in equilibrium $t . C V(i)$ reflects changes in well-being associated with not only changing income, but also changing housing costs and changing endogenous amenity quality. To isolate the welfare gains due to changing housing costs and amenity quality alone, we simply subtract the income growth of a given percentile $i$ from their welfare (i.e., CV) growth:

$$
\Delta \mathcal{W}^{c}(i)=\frac{C V(i)-\left(m_{2}(i)-m_{1}(i)\right)}{m_{1}(i)} .
$$

Whenever $\Delta \mathcal{W}^{c}(i)>0$, income growth understates the increase in well-being at percentile $i$.

Figure 10 reports our headline welfare results for each income decile. It shows the welfare gains from within-city spatial sorting triggered by the 1990-2014 income shift. The left panel 
averages results between homeowners and renters, while the right panel isolates the effects on renters. Focusing first on the average results by decile, we find that the spatial sorting response amplifies the differences in well-being between the rich and the poor during this time period. In the top decile of the income distribution, well-being grew more than income, by an additional 1.4 percentage points. As high earners move downtown, the supply of high quality neighborhoods that they value rises endogenously, making them better off. House prices increase as well, but for high earners the amenity benefit of neighborhood change dominates the price effect. In contrast, at the bottom of the income distribution, households' well-being is hurt by the same house price increases without the same compensatory neighborhood variety benefits. As a result, well-being changes are even lower than income changes, by an additional 0.3 percentage points. Overall, the well-being gap between the top and bottom deciles of the income distribution grew by an additional 1.7 percentage points, compared to the 19 percentage point growth in the nominal income gap. That is, within city spatial sorting amplifies the growing welfare gap between the rich and the poor from rising income inequality by almost 10 percent.

Comparing the welfare results for all households in the left panel of Figure 10 with those for renters only in the right panel, we see that capital gains from house price appreciation benefits households at all income levels, to some extent. For example, about 30 percent of individuals from the lowest income decile who resided downtown in 1990 owned their home, limiting the negative welfare effects of spatial re-sorting. Without this effect - i.e., for renters only - welfare losses of low income households are much larger. Renters in the bottom decile experienced a 0.5 percentage point reduction in their welfare stemming from the changing spatial sorting that resulted from the shift in the income distribution. At the top of the income distribution, the amenity benefit of neighborhood change is strong enough that high income renters still gain from gentrification, in spite of facing the full brunt of the housing cost growth. They see a 0.8 percentage point growth in welfare.

Before analyzing the main mechanisms at play behind these findings, it is worth commenting on the magnitudes of these welfare effects. Figure 10 implies that a renter in the first decile of the income distribution - earning on average $\$ 30,000$ per year - is made roughly $\$ 150$ worse off per year in consumption equivalent terms. There are two reasons for this relatively small overall welfare impact. First, the largest welfare losses from an influx of rich households are concentrated on downtown residents, i.e., only 15 percent of individuals earning $\$ 30,000$ per year live downtown. If we isolate the most impacted group, low income renters who remain downtown, we find a welfare loss that is three times larger, at $\$ 450 .{ }^{36}$ To put that number in perspective, it represents roughly one month's rent for these households. Second, note that we isolate the effect of a change in the income distribution, holding population constant. In reality, population grew a lot in these large CBSAs between 1990 and 2014. Including this population growth along with the changes in the income distribution further amplifies the welfare losses of low income renters by a factor of six, as

\footnotetext{
${ }^{36}$ We only take into account changes in amenities and prices for these households, holding constant their idiosyncratic preference shocks for location.
} 
Figure 10: Welfare Changes From Spatial Sorting Response to Changing Income Distribution
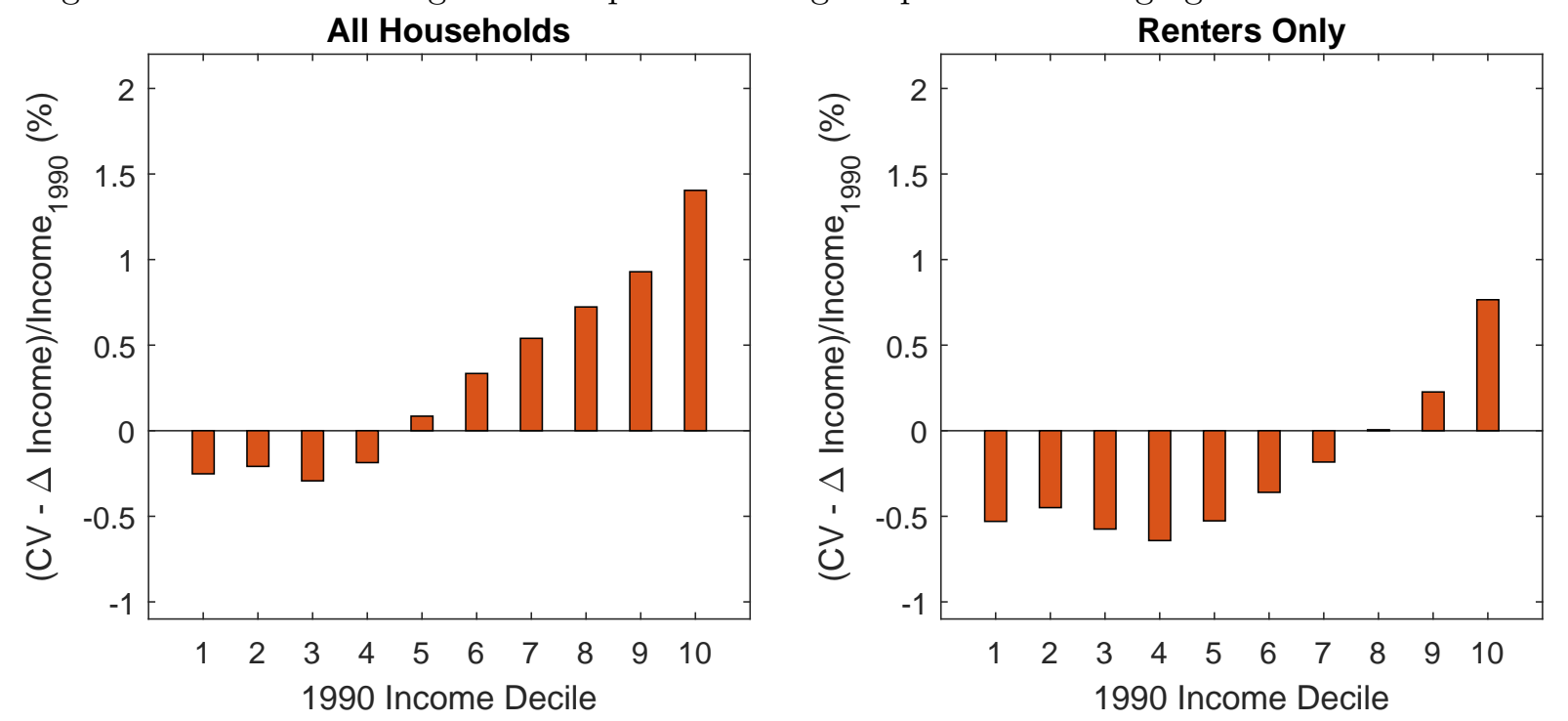

Notes: This figure shows the percent welfare growth that households in each income decile are predicted to receive, above and beyond income growth, between the 1990 and 2014 model equilibria. The left-hand panel shows results averaged across homeowners and renters; the right-hand panel focuses on renters only.

discussed in Appendix E.4. This large magnitude is commensurate with the current policy interest in alleviating the impact of downtown gentrification on this group.

\subsection{Mechanisms}

Two main mechanisms drive our sorting and welfare results. The first is the price mechanism that operates through land markets. As the rich get richer, they move downtown to live in high quality neighborhoods, and to enjoy consumption amenities there. This influx of rich households puts upward pressure on downtown housing prices not only in high quality neighborhoods, but also in low quality ones. The left-hand panel of Figure 11 shows theses house prices change, for different neighborhood types. The model predicts that the shift in the income distribution alone generates a 6 percent increase in house prices in high quality downtown neighborhoods and a 3 percent increase in house prices in low quality downtown neighborhoods. These predicted increases in downtown house prices amount to about 20 percent of the actual increases observed in the data, which again suggest that other factors (like general CBSA population growth) contribute to house price growth. Housing supply is more elastic in the suburbs than downtown, so the model predicts that house prices increase more in low quality areas downtown than in low quality areas in the suburbs $(3 \%$ vs 1\%). This matches the data qualitatively where house price growth between 1990 and 2014 was higher in low quality downtown neighborhoods than in low quality suburban neighborhoods. House price growth in low-quality neighborhoods downtown contributes importantly to the welfare losses of the poor renters who remain downtown.

The second key mechanism behind our results is endogenous supply responses and neighborhood change. As the rich move downtown and demand for high quality neighborhoods increases, 
Figure 11: Mechanisms
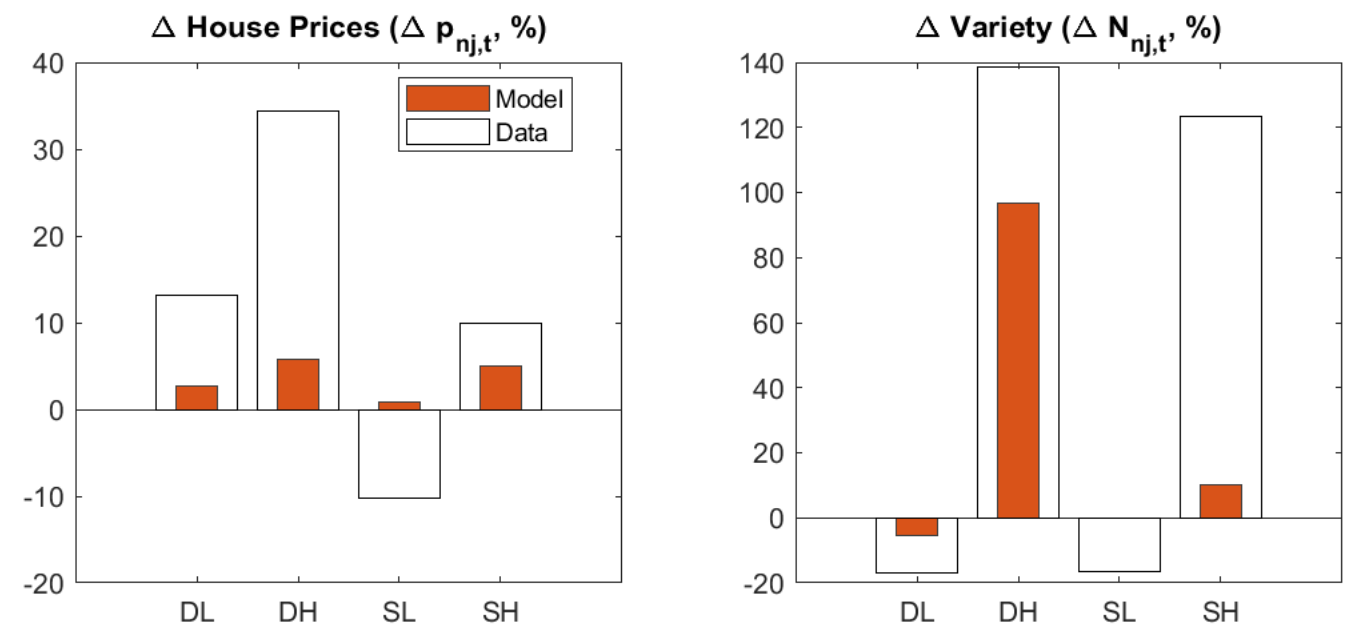

Notes: This figure shows the change in housing costs (on the left) and neighborhood variety (on the right) in each of the four neighborhood types between 1990 and 2014. Red bars are model and wide clear bars are data. Consistent with the model, the change in housing costs are measured in the data for the subset of tracts that maintain the same quality assignment between 1990 and 2014.

developers supply more high quality neighborhoods. Some of this entry is at the cost of exit of lower quality neighborhoods, so that gentrification takes place. The right-hand panel of Figure 11 shows the growth in supply of neighborhoods in each area and quality level. The model predicts a large proportion of the downtown neighborhood change observed in the data (measured as changes in the number of constant geography Census tracts classified as low and high quality, respectively). Given love of variety preferences, the additional entry of high quality neighborhoods downtown makes high income households better off. Poorer households benefit from this entry as well, but this effect is quantitatively limited, because in the data residents of low quality neighborhoods rarely consume amenities in high quality neighborhoods (see Table 3). Overall, the contraction in the number of low quality neighborhoods - the gentrification that we also observe in the data makes low income households worse off. Finally, we note that the predicted supply of high quality neighborhoods also expands in the suburbs, but at a much smaller rate than downtown.

We can use the model to separately quantify the contribution of the price and amenity mechanisms to our welfare results. To that end, we compute a counterfactual that shuts down love of variety effects across neighborhoods by setting the two between-neighborhood substitution elasticities, $\gamma$ and $\sigma$, to infinity. In this counterfactual, prices respond to changes in the income distribution, but the sorting and welfare effects of these price responses are not amplified by responses in neighborhood (or associated consumption amenity) variety. Welfare results are shown in Figure 12 (solid red bars) and contrasted with our baseline quantification (clear bars). The welfare gap across income groups is mitigated substantially when the love of variety effects are shut down, from 1.7 percentage point in the baseline to 0.55 percentage points without love of variety effects. About two-thirds of the welfare gap in our base results stems from the endogenous private amenities re- 
sponse. Interestingly, the absolute welfare losses for the bottom decile gets worse, from -0.25 to -0.5 percentage points, as price increases are not compensated by the gains in consumption amenities that accompany the influx of the rich. Shutting down love of variety effects almost completely eliminates the welfare gains of the rich but increases the welfare losses experienced by the poor.

Figure 12: Shutting Down Amplification

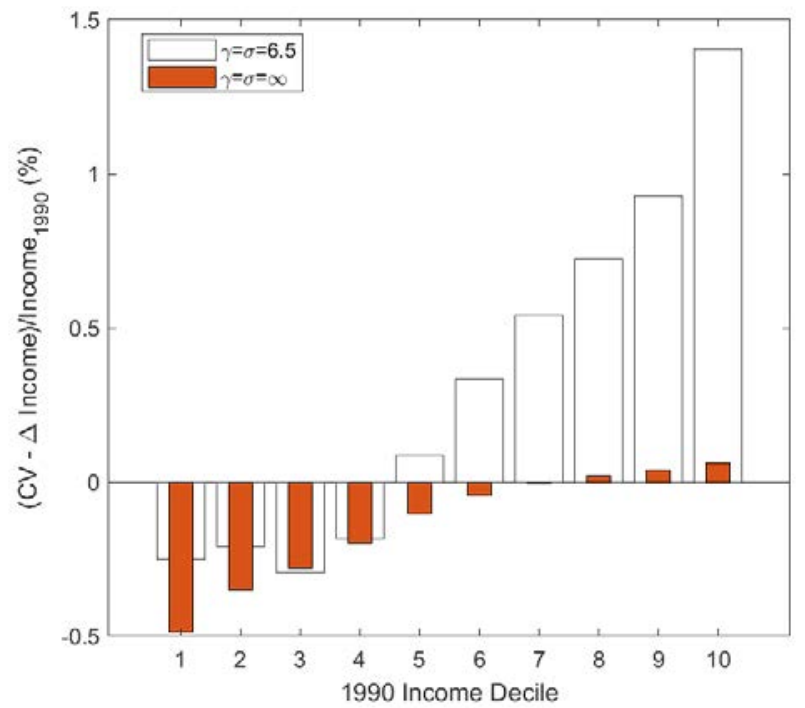

Notes: This figure shows the percent welfare growth that households in each income decile are predicted to receive, above and beyond income growth, between the 1990 and 2014 model equilibria. The left-hand panel shows results averaged across homeowners and renters; the right-hand panel focuses on renters only. The clear bars show the results from the baseline calibration and counterfactual where the neighborhood and amenity love of variety parameters $(\gamma$ and $\sigma$ ) are equal 6.5. The red bars show the welfare results from an alternative calibration and counterfactual where love of variety is shut down by setting these parameters to both equal infinity.

\subsection{Robustness}

To assess the robustness of our results, we perform a series of additional quantitative exercises. Appendix Table E.12 shows the change in welfare and change in propensity to live downtown for the top and bottom income deciles predicted by our model for a range of alternate parameter values. We summarize the key findings here.

Consistent with the underlying economics, spatial sorting and welfare inequality growth predicted by the model in response to growing income inequality are increasing in $\rho$ (which governs the extent of sorting by income), declining in $\gamma$ (which is an inverse measure of love of variety) and declining in $\epsilon_{n}$ (which measures the elasticity of housing supply). Over plausible alternate values for these parameters, however, the quantitative magnitudes generated by our counterfactual exercises are relatively robust. For example, for values of $\rho$ between 2 and 4 and values of $\gamma$ between 5 and 8 , the growth in the downtown share of the top income decile predicted by the model ranges between 40 and 80 percent of that observed in the data, relative to our baseline prediction of 50 percent. Similarly, over these parameter values, the associated growth in the welfare gap between 
the top and bottom deciles ranges between an additional 1.5 and 2 percentage points relative to our baseline of an additional 1.7 percentage points.

Changing $\sigma$ also has small quantitative effects on our counterfactuals. $\sigma$ governs the elasticity of substitution for amenity consumption across neighborhoods. Part of the reason for the relative insensitivity of our results to $\sigma$ is that the amenity share out of non-housing consumption is small ( $\alpha=0.15$ in our baseline). Higher values of $\alpha$ amplifies the in-migration of high income individuals into downtown high quality neighborhoods in response to an increase in the incomes of the rich. Higher values of $\alpha$ also make our counterfactual results more sensitive to $\sigma$. Other potential mitigators that we included in our extended model - such as endogenous public amenities - have even smaller effects on our baseline quantitative results.

\subsection{Gentrification Curbing Policies}

Changes in spatial sorting in large US cities have led to a new policy debate on gentrification and housing affordability. In this final section, we use our model to analyze the potential impact of policies that aim to shape the spatial sorting of heterogeneous households within the city.

Taxing developments We first model a stylized "anti-gentrification" policy, which systematically taxes high quality housing downtown, and uses the proceeds to subsidize rents in low quality neighborhoods downtown (the policy is budget neutral). It aims to limit the development of high quality neighborhoods downtown while helping poorer households to remain located downtown. We compute the counterfactual 2014 spatial equilibrium with a tax on high quality housing downtown of $t=5 \%$. Figure 13 reports the results and contrasts them with our baseline 1990-2014 counterfactual, in order to evaluate how much such a policy would have curbed the gentrification triggered by changes in the income distribution. The left panel shows that the policy stems part of the gentrification of downtown neighborhoods: the inflow of high income households downtown is curbed, as is the outflow of low income families, compared to baseline. The policy is also effective at stemming part of the land price increase downtown, and limiting quality changes. To the extent that governments intrinsically value social diversity within their downtowns, this simulation suggests that such an anti-gentrification policy can help achieve such target.

The well-being effects of this policy, shown in the right panel of Figure 13 are, however, much more muted. The policy attenuates the welfare gains of high income households and welfare losses of low income households, but both effects are small. The policy fails to significantly reduce the losses of low income households because taxing high quality development downtown shifts gentrification - i.e., neighborhood quality and price growth - from downtown to the suburbs. As a result, low income households living in the suburbs experience greater welfare losses relative to baseline. On net, the welfare losses are simply transferred from residents of low quality downtown neighborhoods to residents of low quality suburban neighborhoods.

Appendix Figure E. 8 shows that the results of this policy are very similar to those we obtain when directly modeling zoning regulations; i.e., a policy that imposes a constant relative number 
of high to low quality neighborhoods. The impact on social mixing downtown is significant, but the welfare effects are again very small, as price and quality growth are pushed to the suburbs.

Figure 13: Location Choices and Well-Being under "Anti-Gentrification" Policy
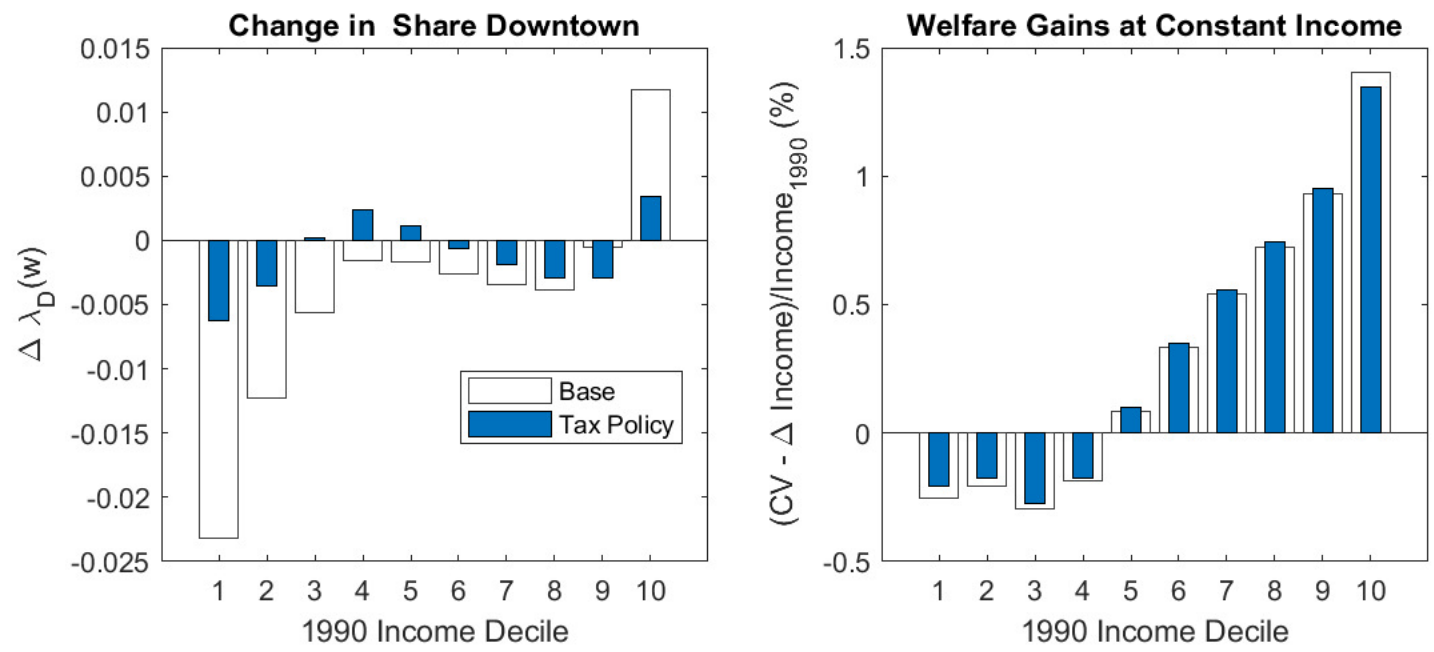

Notes: This figure shows the percent change in the propensity to live downtown (on the left) and change welfare (on the right) that result from the change in the income distribution by income decile. The clear bars show the results from the baseline counterfactual. The blue bars show the results from the alternative counterfactual in which development of high quality neighborhoods downtown is taxed at 5 percent and the proceeds of the tax are redistributed to subsidize housing costs in low quality neighborhoods downtown.

Regulatory constraints on housing supply Finally, we shed light on a policy that has been widely proposed by economists to address the regressive welfare impacts of rising housing costs: relieving regulatory housing supply constraints. Housing regulations do not feature directly into our model, they are instead indirectly captured by the housing supply elasticities that we use in calibration. We now report the effect of doubling the elasticity of housing supply both downtown and in the suburbs. Figure 14 shows that doing so does little to stem neighborhood change downtown (in the left panel) but it mitigates the associated welfare losses on the poor (in the right panel). House price growth is reduced by approximately 1 percentage point in all neighborhoods, and effectively shut down in the suburbs. The benefits of this slowed house price growth mostly accrue to the poor - the lowest income decile's welfare loss drops by over two-thirds, from 0.25 to 0.08 percentage points. Welfare inequality continues to grow, however, because the rich gain from increased neighborhood variety that persists with the increased elasticity of housing supply. 
Figure 14: Effects of Increasing Supply Elasticity
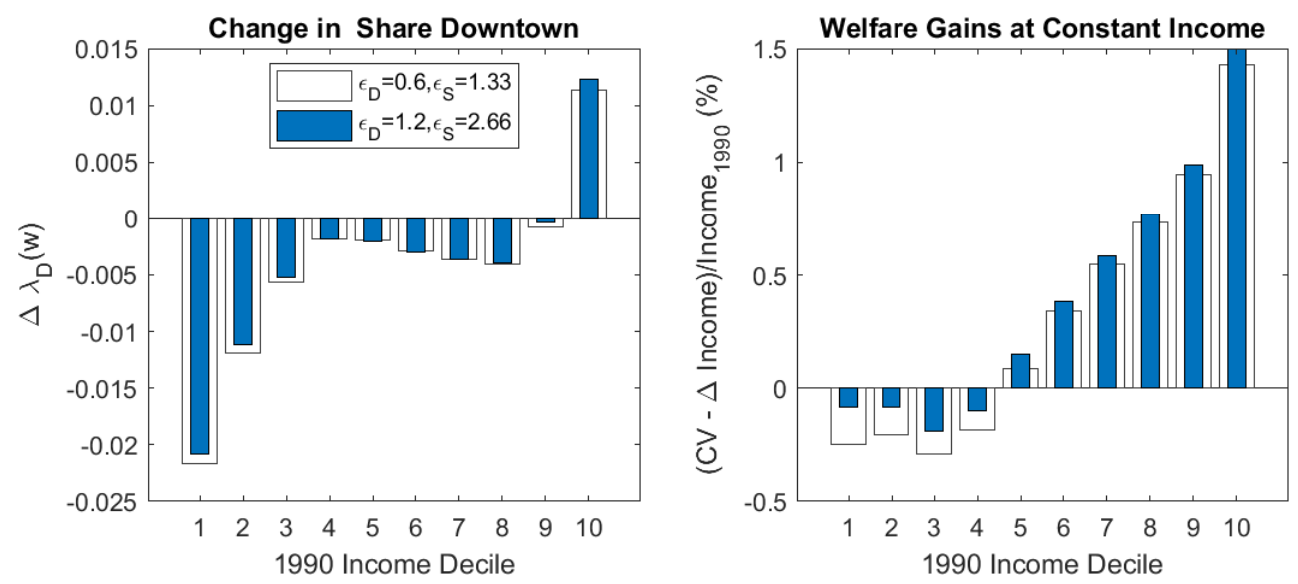

Notes: This figure shows the percent change in the propensity to live downtown (on the left) and change welfare (on the right) that result from the change in the income distribution by income decile. The clear bars show the results from the baseline counterfactual. The blue bars show the results from the alternative counterfactual where the elasticity of housing supply is double its baseline level in both the suburbs and downtown.

\section{Conclusion}

We set out to explore the link between rising incomes at the top of the income distribution and changes in the urban landscape of U.S. cities in the past few decades: high income households have been moving into downtowns, where housing prices have gone up and neighborhoods have been changing dramatically. These changes have lead to anti-gentrification protests and a renewed interest in policy circles for maintaining social diversity in urban neighborhoods. To study this phenomenon, we develop a spatial model of a city with heterogeneous agents, neighborhoods of different qualities, and non-homothetic preferences. We quantify the model and use it to tease out how much of the change in spatial sorting patterns by income over time can be plausibly traced back to changes in the income distribution, tilted towards higher incomes.

Our estimates suggest that rising incomes at the top of the distribution were a substantive contributor to increased urban neighborhood change during the last 25 years within the U.S. The analysis also suggests that neighborhood change resulting from the increased incomes of the rich did make poorer residents worse off. Accounting for the spatial sorting response resulting from the change in income distribution between 1990 and 2014 exacerbates the growing inequality between the top and bottom income decile by an additional 1.7 percentage points.

We explore possible policy responses to mitigate these distributional impacts of neighborhood change. We find that policies that contain gentrification seem to only lead to a very modest mitigation of the increase in well-being inequality, which could arguably be targeted more efficiently by direct redistribution. On the other hand, these policies are effective at maintaining social diversity in urban neighborhoods, arguably one of the goals of such policies.

In this paper, we have focused on the within-city consequences of a rise in top incomes. By doing so, we have highlighted one mechanism that has contributed to shape neighborhood change in 
the past twenty five years: the rising incomes of the rich coupled with non-homothetic preferences for location across income groups. In order to conduct this analysis, we have developed a model that is stylized in some dimensions, but is very flexible. It is in particular amenable to study other sources of changes in within-city spatial sorting that are potentially empirically relevant. Using our framework to study other potential causes of neighborhood change is a natural avenue for future research. 


\section{References}

Agarwal, Sumit, J Bradford Jensen, and Ferdinando Monte, "The geography of consumption," 2019.

Aguiar, Mark and Mark Bils, "Has consumption inequality mirrored income inequality?," American Economic Review, 2015, 105 (9), 2725-56.

Ahlfeldt, Gabriel M, Stephen J Redding, Daniel M Sturm, and Nikolaus Wolf, "The economics of density: Evidence from the Berlin Wall," Econometrica, 2015, 83 (6), 2127-2189.

Allen, Treb, Costas Arkolakis, and Xiangliang Li, "Optimal city structure," Yale University, mimeograph, 2015.

Almagro, Milena and Tomas Dominguez-Iino, "Location Sorting and Endogenous Amenities: Evidence from Amsterdam," 2019.

ao, Rodrigo Ad Michal Kolesr, and Eduardo Morales, "Shift-share designs: Theory and inference," Working Paper 24944, National Bureau of Economic Research August 2018.

Armour, Philip, Richard V Burkhauser, and Jeff Larrimore, "Using the Pareto distribution to improve estimates of topcoded earnings," Economic Inquiry, 2016, 54 (2), 1263-1273.

Athey, Susan, David Blei, Robert Donnelly, Francisco Ruiz, and Tobias Schmidt, "Estimating heterogeneous consumer preferences for restaurants and travel time using mobile location data," AEA Papers and Proceedings, 2018, 108, 64-67.

Atkin, David, Benjamin Faber, and Marco Gonzalez-Navarro, "Retail globalization and household welfare: Evidence from Mexico," Journal of Political Economy, 2018, 126 (1), 1-73.

Autor, David H., Christopher J. Palmer, and Parag A. Pathak, "Gentrification and the amenity value of crime reductions: Evidence from rent deregulation," 2017, (23914).

Baum-Snow, Nathaniel and Daniel Hartley, "Accounting for central neighborhood change, 1980-2010," 2018, (2016-09).

- and Justin Marion, "The effects of low income housing tax credit developments on neighborhoods," Journal of Public Economics, 2009, 93 (5-6), 654-666.

_ and Lu Han, "The Microgeography of Housing Supply," 2019.

Berkes, Enrico and Ruben Gaetani, "Income segregation and rise of the knowledge economy," Ohio State University Mimeo, 2018.

Borusyak, Kirill, Peter Hull, and Xavier Jaravel, "Quasi-experimental shift-share research designs," Working Paper 24997, National Bureau of Economic Research 2018. 
Brueckner, Jan K, Jacques-François Thisse, and Yves Zenou, "Why is central Paris rich and downtown Detroit poor?: An amenity-based theory," European Economic Review, 1999, 43 (1), $91-107$.

Brummet, Quentin and Davin Reed, "The effects of gentrification on original neighborhood residents: Evidence from longitudinal Census microdata," Working Paper 19-30, Federal Reserve Bank of Philadelphia 2019.

Chen, M Keith and Ryne Rohla, "The effect of partisanship and political advertising on close family ties," Science, 2018, 360 (6392), 1020-1024.

Couture, Victor, "Valuing the Consumption Benefits of Urban Density," Technical Report, University of California, Berkeley. Processed 2016.

_ and Jessie Handbury, "Urban revival in America, 2000 to 2010," 2017, (24084).

_, Jonathan Dingel, Allison Green, and Jessie Handbury, "Quantifying social interactions using smartphone data," Work in Progress.

Davis, Donald R and Jonathan I Dingel, "The comparative advantage of cities," April 2019.

_ , _, Joan Monras, and Eduardo Morales, "How segregated is urban consumption?," Journal of Political Economy, Forthcoming.

Davis, Morris A and Francois Ortalo-Magne, "Household expenditures, wages, rents," Review of Economic Dynamics, 2011, 14 (2), 248-261.

Dekle, Robert, Jonathan Eaton, and Samuel Kortum, "Unbalanced trade," American Economic Review, 2007, 97 (2), 351-355.

Diamond, Rebecca, "The determinants and welfare implications of US workers' diverging location choices by skill: 1980-2000," American Economic Review, 2016, 106 (3), 479-524.

_ and Tim McQuade, "Who wants affordable housing in their backyard? An equilibrium analysis of low-income property development," Journal of Political Economy, 2019, 127 (3), $1063-1117$.

_, Timothy McQuade, and Franklin Qian, "The effects of rent control expansion on tenants, landlords, and inequality: Evidence from San Francisco," American Economic Review, Forthcoming.

Ding, Lei, Jackelyn Hwang, and Eileen Divringi, "Gentrification and residential mobility in Philadelphia," Regional Science and Urban Economics, 2016, 61, 38-51.

Dingel, Jonathan I, "The determinants of quality specialization," The Review of Economic Studies, 2016, 84 (4), 1551-1582. 
Disdier, Anne-Célia and Keith Head, "The puzzling persistence of the distance effect on bilateral trade," The Review of Economics and Statistics, 2008, 90 (1), 37-48.

Edlund, Lena, Cecilia Machado, and Michaela Sviatchi, "Bright minds, big rent: Gentrification and the rising returns to skill," 2019, (21729).

Einav, Liran, Peter J Klenow, Benjamin Klopack, Jonathan D Levin, Larry Levin, and Wayne Best, "Assessing the gains from e-commerce," 2019.

Ellen, Ingrid Gould and Katherine ORegan, "Crime and urban flight revisited: The effect of the 1990s drop in crime on cities," Journal of Urban Economics, 2010, 68 (3), 247-259.

_ , Keren Mertens Horn, and David Reed, "Has falling crime invited gentrification?," 2019, (CES 17-27).

Eriksen, Michael D and Stuart S Rosenthal, "Crowd out effects of place-based subsidized rental housing: New evidence from the LIHTC program," Journal of Public Economics, 2010, 94 (11-12), 953-966.

Faber, Benjamin, "Trade liberalization, the price of quality, and inequality: Evidence from mexican store prices," UC-Berkeley Working Paper, 2014.

_ and Thibault Fally, "Firm heterogeneity in consumption baskets: Evidence from home and store scanner data," 2017.

Fajgelbaum, Pablo and Cecile Gaubert, "Optimal spatial policies, geography and sorting," 2018.

Fajgelbaum, Pablo D and Amit K Khandelwal, "Measuring the unequal gains from trade," The Quarterly Journal of Economics, 2016, 131 (3), 1113-1180.

_ , Eduardo Morales, Juan Carlos Suárez Serrato, and Owen Zidar, "State taxes and spatial misallocation," The Review of Economic Studies, 2018, 86 (1), 333-376.

Fajgelbaum, Pablo, Gene M. Grossman, and Elhanan Helpman, "Income distribution, product quality, and international trade," Journal of Political Economy, 2011, 119 (4), 721-765.

Fogli, Alessandra and Veronica Guerrieri, "The end of the American Dream? Inequality and segregation in US cities," University of Chicago Booth School of Business, 2019.

Gaigne, Carl, Hans Koster, Fabien Moizeau, and Jacques-Francois Thisse, "Amenities and the social structure of cities," HSE Working paper WP BRP 162/EC/2017, National Research University Higher School of Economics 2017.

Glaeser, Edward, Jed Kolko, and Albert Saiz, "Consumer city," Journal of Economic Geography, 2001, 1 (1), 27-50. 
Guerrieri, Veronica, Daniel Hartley, and Erik Hurst, "Endogenous gentrification and housing price dynamics," Journal of Public Economics, 2013, 100, 45-60.

Gyourko, Joseph, Christopher Mayer, and Todd Sinai, "Superstar cities," American Economic Journal: Economic Policy, 2013, 5 (4), 167-199.

Handbury, Jessie, Ilya Rahkovsky, and Molly Schnell, "Is the focus on food deserts fruitless? Retail access and food purchases across the socioeconomic spectrum," 2015.

Hoelzlein, Mattias, "Two-Sided Sorting and Spatial Inequality in Cities," 2019.

Holian, Matthew J. and Matthew E. Kahn, "The impact of center city economic and cultural vibrancy on greenhouse gas emissions from transportation," MTI Report 11-13, Mineta Transportation Institute 2012.

Hsieh, Chang-Tai and Enrico Moretti, "Housing constraints and spatial misallocation," American Economic Journal: Macroeconomics, April 2019, 11 (2), 1-39.

Jaravel, Xavier, "The unequal gains from product innovations: Evidence from the US retail sector," The Quarterly Journal of Economics, 2018, 134 (2), 715-783.

Lance Freeman, "Displacement or succession?: Residential mobility in gentrifying neighborhoods," Urban Affairs Review, 2005, 40 (4), 463-491.

Lester, T. William and Daniel A. Hartley, "The long term employment impacts of gentrification in the 1990s," Regional Science and Urban Economics, 2014, 45 (1), 80-89.

McKinnish, Terra, Randall Walsh, and T. Kirk White, "Who gentrifies low-income neighborhoods?," Journal of Urban Economics, 2010, 67 (2), 180-193.

Meltzer, Rachel and Pooya Ghorbani, "Does gentrification increase employment opportunities in low-income neighborhoods?," Regional Science and Urban Economics, 2017, 66 (C), 52-73.

Monte, Ferdinando, Stephen J Redding, and Esteban Rossi-Hansberg, "Commuting, migration and local employment elasticities," American Economic Review, 2018, 108 (12), 38553890.

Neumark, David, Junfu Zhang, and Brandon Wall, "Employment dynamics and business relocation: New evidence from the National Establishment Time Series," in "Aspects of worker well-being," Emerald Group Publishing Limited, 2007, pp. 39-83.

Peters, Michael, Fabian Eckert et al., "Spatial structural change," in "2018 Meeting Papers" number 98 Society for Economic Dynamics 2018.

Piketty, Thomas, Emmanuel Saez, and Gabriel Zucman, "Distributional national accounts: methods and estimates for the United States," The Quarterly Journal of Economics, 2017, 133 (2), 553-609. 
Redding, Stephen J and Daniel M Sturm, "Estimating neighborhood effects: evidence from war-time destruction in London," Princeton University, mimeograph, 2016.

Redding, Stephen J. and Esteban Rossi-Hansberg, "Quantitative spatial economics," $A n$ nual Review of Economics, 2017, 9 (1), 21-58.

Ruggles, Steven, Sarah Flood, Ronald Goeken, Josiah Grover, Erin Meyer, Jose Pacas, and Matthew Sobek, "IPUMS-USA," 2018.

Saiz, Albert, "The geographic determinants of housing supply," The Quarterly Journal of Economics, 2010, 125 (3), 1253-1296.

Small, Kenneth A, Erik T Verhoef, and Robin Lindsey, The economics of urban transportation, Routledge, 2007.

Su, Yichen, "Measuring the value of urban consumption amenities: A time-use approach," 2018.

_ , "The rising value of time and the origin of urban gentrification," 2018.

Tsivanidis, Nick, "The aggregate and distributional effects of urban transit infrastructure: Evidence from Bogotás TransMilenio," Technical Report, University of Chicago Booth School of Business 2019.

Vigdor, Jacob L., Douglas S. Massey, and Alice M. Rivlin, "Does gentrification harm the poor?," Brookings-Wharton Papers on Urban Affairs, 2002, pp. 133-182. 